\title{
ATTRIBUTIONS FOR BRAIN INJURED PERSONS' ACTIONS: EFFECTS OF CAUSE OF INJURY AND FAMILIARITY
}

\section{Lynette Ann Foster}

\author{
A thesis \\ submitted to Victoria University of Wellington \\ in fulfilment of the \\ requirements for the degree of \\ Master of Science \\ in Psychology
}

Victoria University of Wellington

March 2010 


\section{Table of Contents}

Acknowledgments....................................................................................... 1

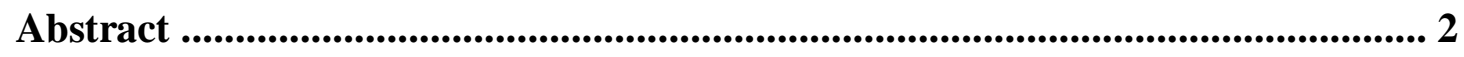

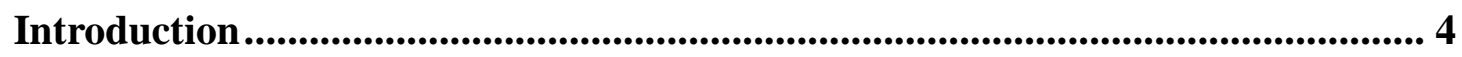

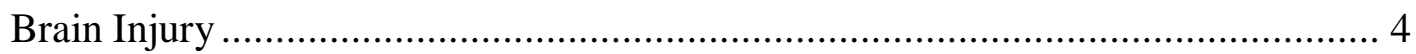

Misconceptions about Brain Injuries ................................................................... 5

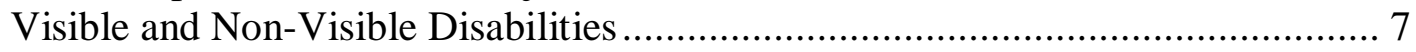

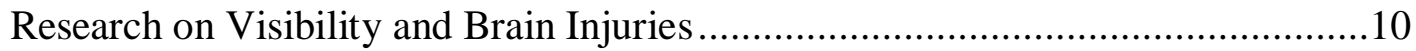

Stereotyping, Discrimination, Prejudice, and Stigma......................................13

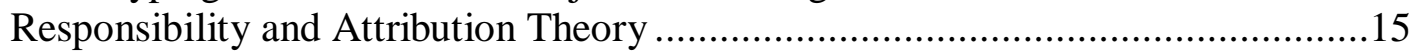

Familiarity with Individuals with Brain Injury .............................................17

The Current Research .............................................................................19

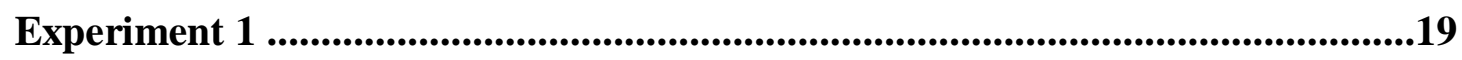

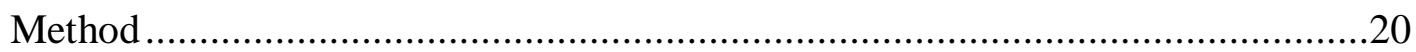

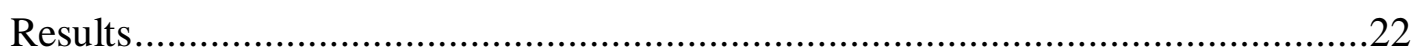

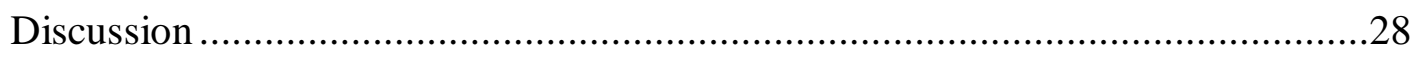

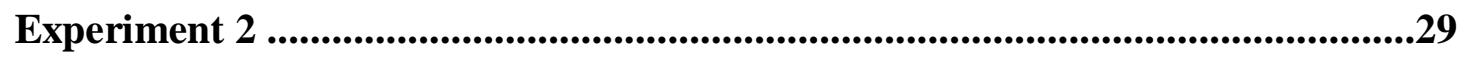

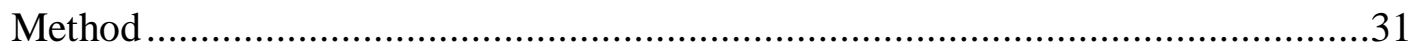

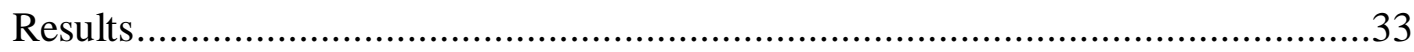

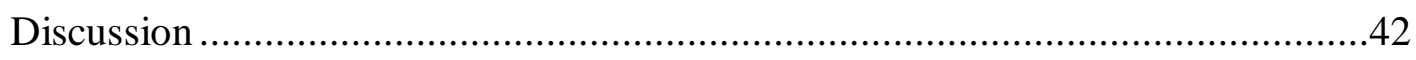

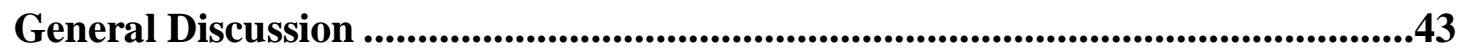

Effects of Providing Information about the Brain Injury ..................................44

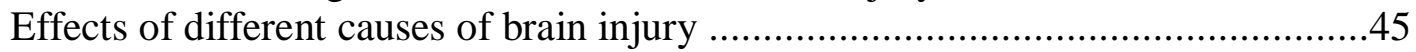

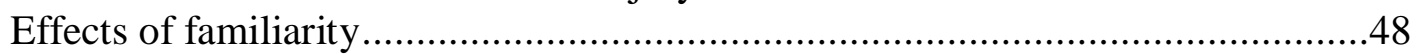

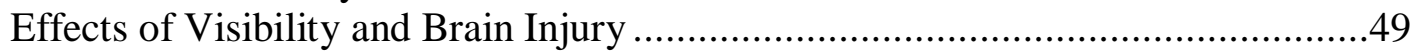

Stereotyping, Prejudice, Discrimination and Stigma .......................................51

Responsibility and Weiner's Attribution Theory ............................................53

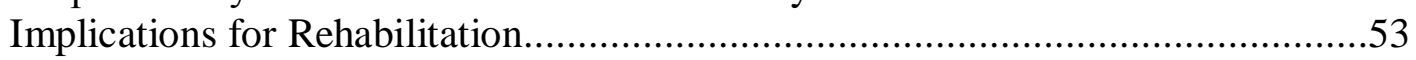

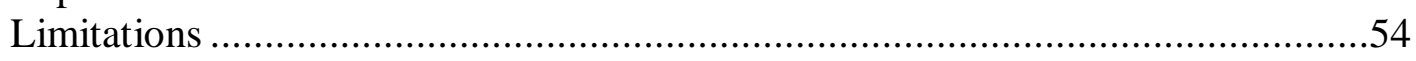

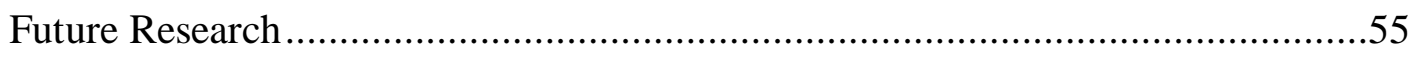

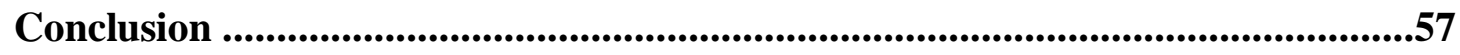

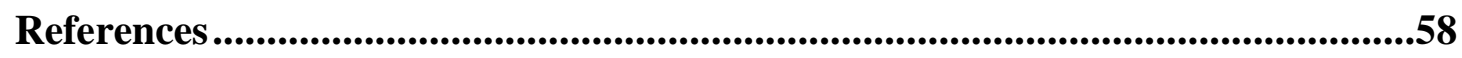

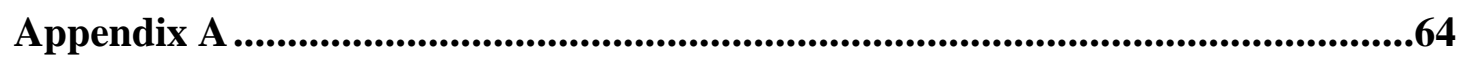

Photos

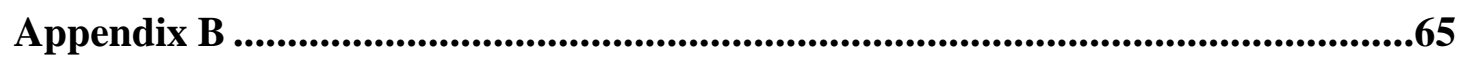

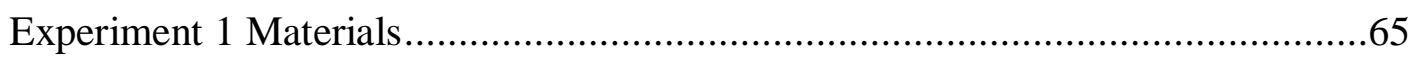

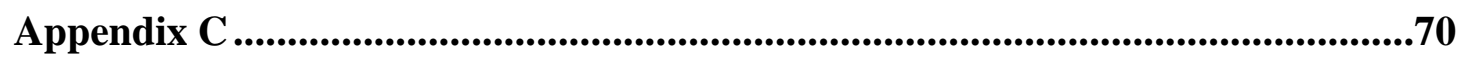

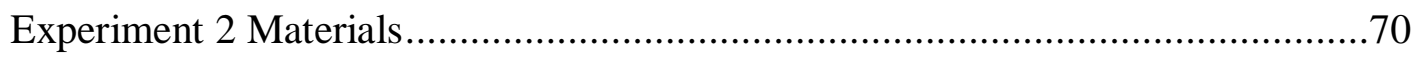




\section{Acknowledgments}

I would like to thank John McClure (my primary supervisor) for his encouragement and support when engaging me in this project and his perseverance in making me the best writer I could be. Similarly I would like to thank John McDowall (my second supervisor) for his encouragement and availability to answer any queries or concerns I had. Their combined assistance and uniqueness was much appreciated and integral in enhancing my analytical and written skills. I would also like to acknowledge Paul Jose who was always willing to listen to, or read my ideas on statistical analysis and discuss them with me. Finally, I would like to thank my partner, Neil de Wit for supporting me during this time and taking the time to read my drafts, even when he felt he did not understand the topic! Many thanks also go to my children, Jessica and Katie for allowing me the time to complete my studies and assist in running our household. 


\begin{abstract}
Misunderstanding the behaviours of individuals with brain injuries is common and may result in negative consequences, especially when visible markers of brain injury are absent. Previous research on this issue manipulated the visibility of a brain injury with photographs of an adolescent with either a head scar or no scar (McClure, Buchanan, McDowall, \& Wade, 2008). Scenarios stated that the adolescent had suffered a brain injury, followed by undesirable changes in four behaviours. Participants attributed the behaviors more to adolescence relative to brain injury when there was no scar than when there was a scar. The current research extends this research by examining the effects of visible markers of injury combined with three other factors: whether people are informed about the injury, the stated cause of injury, and familiarity with individuals with brain injury.

Experiment $1(N=98)$ examined the effects of informing people about brain injury and found that when participants were not informed about the brain injury, visible markers of injury had no effect on attributions; participants made higher attributions to adolescence than brain injury in both scar conditions. In contrast, when participants were informed about the injury, in the no scar condition, attributions were higher for adolescence than brain injury whereas in the scar condition, both causes were rated equally.

Experiment $2(N=148)$ examined the effects of putative causes of the injury and the participants' familiarity with the brain injury. The results found that visible markers of injury had no effect on attributions when the described cause was a brain tumour, but when the described cause was abusing illegal drugs, participants made higher attributions to brain injury than adolescence in the scar condition, with the reverse found in the no scar condition. In the scar condition,
\end{abstract}


participants with high familiarity attributed the behaviours more to the brain injury than participants with low familiarity and participants with low familiarity attributed the behaviours more to adolescence than participants with high familiarity. In the no scar condition, participants in both familiarity groups attributed the behaviours equally to adolescence and brain injury.

This research shows that the visibility of a brain injury, the etiology of an injury and familiarity with individuals with brain injury influence people's attributions for an adolescent's undesirable behavior. This information can be used by professionals and caregivers to inform survivors about these effects and used in campaigns to educate the public. 


\section{Introduction}

\section{Brain Injury}

A variety of young and old people throughout the world sustain brain injuries every year (Abelson-Mitchell, 2008). Typical patients include males between the ages of 15 and 25 years and older people, and the most common causes of the injuries are road traffic accidents and falls respectively (see review by Abelson-Mitchell). In the USA, 1.4 million people sustain a traumatic brain injury (TBI) every year; however, it is estimated that this figure is conservative because individuals who suffer mild TBI often do not seek treatment (Brain Injury Association of America, 2009). Similarly, statistics in New Zealand are estimated due to the variations in definitions and poor coding of TBI in hospitals and, as in the USA, some individuals with mild TBI do not seek treatment (Accident Compensation Commission (ACC), 2006). Christchurch hospital reported 2133 cases of TBI in 2004 (ACC) and Brain Injury New Zealand claim that 90 New Zealanders suffer a brain injury every day (Brain Injury New Zealand, 2009). In 2004, ACC, an organisation which provides personal injury cover for all New Zealanders and visitors to New Zealand, made payments in excess of \$100 million for concussion and TBI treatment.

The causes of brain injuries vary considerably. Brain tumours, infections, strokes, hypoxia (lack of oxygen to the brain), drugs, alcohol, pesticides, solvents and gases can all potentially lead to a brain injury (Brain Injury New Zealand, 2009). Traumatic brain injuries are a result of external trauma to the brain (Snyder, Nussbaum \& Robins, 2006). The trauma could be an open head injury (an object penetrating the skull) or a closed head injury (blunt force trauma with no skull 
penetration) resulting from a variety of accidents (road traffic, fall, gunshot or sporting accidents) (Snyder et al.).

These statistics and information highlight the economic and social costs of brain injuries to individuals and society. Other factors which may affect survivors of brain injuries, their caregivers and family are secondary complications. As a result of substantive injuries, survivors of TBI may experience secondary complications such as attention, memory and executive functioning impairments (Draper \& Ponsford, 2008). Additional complications can include depression (Tsaousides, Ashman \& Seter, 2008), mania, aggression, post traumatic stress disorder (Kim et al., 2007) and behavioural and personality problems (Willer, Johnson, Rempel \& Linn, 1993). A factor which can influence depression is employment difficulties; when survivors perceive that their employment needs are met, levels of depression are lower (Tsaousides et al.). This implies that individuals with TBI who are unable to re-enter the work force as a result of reduced capacity or discrimination are likely to have additional or increased mental health issues.

Also, Dawson and Chipman (1995) found that up to $90 \%$ of adult survivors of TBI experience social handicap (physical dependence, employment and social integration problems). Not only do survivors of TBI experience debilitating physical, mental, personality and behavioural difficulties (Willer et al., 1993), they also have to contend with misconceptions by the public and health professionals which may result in discriminatory practices.

\section{Misconceptions about Brain Injuries}

Misconceptions about the subsequent effects of brain injury and the process of recovery from brain injury are common and can affect survivor's rehabilitation. The general public and non-expert health professionals hold a number of 
misconceptions regarding recovery from brain injury. Swift and Wilson (2001) found that survivors of brain injury, caregivers and rehabilitation professionals report that it is common for the general public to believe that people's brain injuries will recover as quickly as their physical injuries. Furthermore, they believe that once individuals with brain injury are treated and discharged from hospital, they are physically and mentally well. The public and non-expert health professionals also exhibit a lack of understanding about the functioning and recovery associated with brain injury. They fail to appreciate that, for survivors of TBI, the ability to perform tasks can vary from day to day (Swift \& Wilson). They also believe that undesirable behaviours caused by a brain injury will improve when, in some instances, these behaviours persist (Swift \& Wilson).

A potentially harmful misconception is that recovery is dependent on the effort expended by survivors (Gouvier, Prestholdt and Warner, 1988). Further misconceptions include the lack of awareness of the time frames involved in recovery and the effect that non-visible injuries have on health professionals' attitudes towards survivors (Chamberlain, 2006). These misconceptions can lead to inferences of 'malingering' from the public and health professionals (Chamberlain).

The finding that little change occurred in the public's misconceptions about moderate to severe TBI from 1991 to 2004 may highlight the lack of effort and attention given to modifying these misconceptions (Guilmette \& Paglia, 2004). Also, the nature and extent of these common misconceptions regarding TBI impedes survivors' re-integration into society (Willer et al., 1993) and may fuel discriminatory practices. Conflicting information and advice from professionals further hinders survivors' efforts at recovery (Chamberlain, 2006). 
Misconceptions about cognitive and behavioural symptoms resulting from brain injuries also impede survivors' recovery efforts. Symptoms such as memory impairments, aggressive behaviour and a lack of motivation can have causes other than brain injury (Swift \& Wilson, 2001). Because of this they are not typically recognised by the public and non-expert health professionals as symptoms of brain injury (Swift \& Wilson), which may result in those symptoms not being given the appropriate attention and treatment. This lack of awareness of the subsequent effects of brain injuries may result in people attributing behaviours or symptoms resulting from a brain injury to other factors. For example, McClure, Devlin, McDowall and Wade (2006) found that when an adolescent had no visible markers of brain injury, participants attributed his undesirable behaviour (angers quickly, lacks motivation, sleeps a lot and lacks self-confidence) more to his adolescence than his brain injury.

\section{Visible and Non-Visible Disabilities}

Whether a disability is visible or not visible also influences other people's reactions towards individuals with disabilities. Miller and Sammons (1999) suggest that people categorise other people into either disabled or abled then distinguish between the two using visual and/or auditory cues (stereotyping). Individuals with obvious signs of disability, such as scars or medical aids, are placed in the disabled category and our expectations of these individuals are different from non-disabled individuals (Miller \& Sammons). In contrast, individuals with no visible signs of disabilities, who are not categorised as disabled, are placed into categories based on stereotypes, expectations and life experiences (Miller \& Sammons).

Other social and cognitive psychological factors which influence judgements about individuals with visible and non-visible disabilities include the 
availability of information and the salience of stimuli. The availability heuristic leads people to use information that is easily recalled or accessible; this information is then used when making causal judgements about others' behaviour (Tversky \& Kahneman, 1974). For example, when an adolescent's brain injury is not visible, people may select easily recalled information (adolescent norms) as opposed to less familiar information (brain injury) when making judgements about the cause of the adolescent's undesirable behaviour. This may occur because people are generally more familiar with adolescents than with brain injuries.

The salience of stimuli also influences causal judgements; salient stimuli elicit more attention, which results in more details of the salient stimuli being encoded relative to less salient stimuli, thereby facilitating greater recall of the salient stimuli (Fiske, Kenny \& Taylor, 1982). This results in disproportionate attributions to the salient stimuli (Fiske et al.). Related research by Rohmer and Louvet (2009) found that visible disabilities were a superordinate social category, where the disability was more salient than gender or ethnicity.

Individuals with no visible markers of disability have to decide whether they will disclose their disability to others and how they will manage the disclosure. They may have concerns about disclosing their disability as they may be anxious about the accompanying stigma or shame and want to be viewed "only" or "firstly" as a person (Goffman, 1963; Matthews \& Harrington, 2000). Furthermore, self-disclosure costs (stereotyping, avoidance, unwanted sympathy and negative impacts on relationships) may potentially outweigh the momentary rewards (social support) associated with disclosing a disability (Matthews \& Harrington). Therefore, unless essential for practical reasons, self-disclosure is often avoided by individuals with no visible markers of disability (Matthews \& 
Harrington). If non-disclosure is chosen, individuals with non-visible disabilities may spend considerable time and energy ensuring that their symptoms are concealed (Goffman).

The impact of disclosing a disability or illness to others may be further exacerbated when the person is an adolescent. Adolescence is a time of self doubt about appearance, where adolescents have a fear of being judged about how they dress, behave or talk and are preoccupied with differences between themselves and others (Miller \& Sammons, 1999). These self doubts may be compounded when the adolescent has to decide whether to disclose or not disclose a non-visible disability.

HIV (Human Immunodeficiency Virus) is another non-visible illness and a review by Cline and McKenzie (2000) found that some individuals with HIV choose non-disclosure to avoid being stigmatised and the resulting discrimination. However, choosing non-disclosure means forsaking the social support received through disclosure. It is possible that those survivors of brain injury who have no visible markers of injury choose non-disclosure for the same reasons as individuals with HIV.

Other factors which affect the wellbeing of individuals with non-visible disabilities are symptom variability and medical professionals' reactions. As a result of symptom variability (feeling well one day and incapacitated the next), friends and family may doubt the severity of their illness (see review by Matthews \& Harrington, 2000). This doubt about the severity of an illness may be compounded by medical professionals who fail to legitimise brain injury survivors' symptoms (Chamberlain, 2006). In these situations, responses from professionals were often lacking, reducing survivors' feeling of hope and negatively impacting 
their attitudes about recovery (Chamberlain). Also, a lack of awareness of the survivors' feeling of invisibility and a lack of empathy and support from professionals prompts some survivors of brain injury to use private, as opposed to public, clinical services (Chamberlain).

Although uncommon, in some instances, visible markers of injury can be beneficial and consequently increase social support and communication. For instance, Zahn (1973) found that young people receiving disability benefits had better interpersonal relations than older people, when their markers of disability were visible (wheelchair, crutches, braces). Zahn implied that this was due to the visible markers of sickness or disability legitimising their current situation. Furthermore, ambiguity regarding an individual's health status (when a disability was not clearly indicated) resulted in greater interpersonal problems (Zahn). In this instance, visible markers of disability assist the disabled. However the visibly disabled also experience stereotyping, avoidance and hostile feelings (Matthews \& Harrington, 2000) and have to manage the anxiety caused by anticipating other people's stigmatising attitudes and behaviours (Goffman, 1963). Furthermore, stigma research shows that people with visible disabilities are often the targets of prejudice and discrimination (Latner, Stunkard \& Wilson, 2005; Matthews \& Harrington).

\section{Research on Visibility and Brain Injuries}

McClure et al. (2006) clarified the effect of visible markers of disability. Based on the theory that salient stimuli influence causal judgements (Fiske et al., 1982), McClure et al. predicted that salient stimuli, such as visible markers of brain injury, were likely to activate information about brain injuries, but when there were no visible markers of injury, other factors, such as adolescent norms, would be 
invoked as causes for an injured adolescent's undesirable behaviour. They found that undesirable behaviours that had been rated as common for both adolescents and individuals with brain injury (sleeps a lot, angers quickly, lacks motivation and lacks self-confidence) were attributed equally to adolescence and brain injury when there were visible markers of injury (a head bandage). When there were no visible markers of injury, participants attributed the behaviours more to adolescence than brain injury.

Expanding on McClure et al.'s (2006) research, McClure, Buchanan, McDowall and Wade (2008) found similar patterns of attributions when participants were shown an adolescent with a head scar, as opposed to a bandaged head. Participants rated the injury as more severe when there were visible markers of injury (scar), and higher perceptions of severity correlated with lower attributions to adolescence and higher attributions to brain injury (McClure et al., 2008). Even though participants were informed that the adolescent had suffered a brain injury, this attribution pattern still occurred.

McClure et al.'s (2006; 2008) research shows that people's attributions regarding an adolescent's undesirable behaviour are influenced by visible markers of injury and the perceived severity of the brain injury. One interpretation of these findings is that participants applied stereotypes about adolescent norms when there were no visible markers of injury because the behaviours described were highly typical adolescent behaviours. Even though participants were advised about the adolescent's brain injury they still attributed the behaviours more to adolescence than brain injury when there were no visible markers of brain injury. This implies that people attribute behaviour based on the availability of information (accessible information) and discounting. That is, people discount the less available 
information (brain injury) in favour of more available information (adolescence) when there are no visible markers of injury (McClure et al., 2008).

In contrast, visible markers of injury lead to higher attributions to brain injury, suggesting that a scar made the disability more salient than adolescence, thereby enhancing attributions to the brain injury. As previously mentioned, Rohmer and Louvet (2009) found that visible disabilities were more salient than gender or ethnicity. Extrapolating from Rohmer and Louvet's research, visible markers of brain injury may have been a superordinate social category in McClure et al.'s (2008) scar conditions, whereby the salience of the brain injury was increased as a result of the scar, resulting in the brain injury being more salient than adolescence, when participants attributed causes for the undesirable behaviours. This potentially explains why visible markers of injury prompt people to attribute the behaviours more to the brain injury in McClure et al.'s research. To summarise, McClure et al.'s $(2006 ; 2008)$ research suggests that stereotypes, the availability of information and the salience of stimuli can all potentially lead people to attribute an adolescent's undesirable behaviour resulting from a head injury to other causes, depending on whether the injury is visible or not visible.

An implication of McClure et al.'s $(2006 ; 2008)$ research is that having no visible markers of brain injury can be problematic for survivors of brain injury, because little allowance is given to the injury as the cause of the undesirable behaviour. This suggests there is a cost to having no visible markers of injury, as participants attributed the undesirable behaviours more to adolescence than to brain injury (McClure, 2009). In contrast, in terms of identifying likely causes of behaviours resulting from the injury, it was beneficial to have visible markers of injury because participants attributed the undesirable behaviours more to the brain 
injury. These findings contrast with research on prejudice and discrimination which have shown that a cost is associated with having visible markers of disability (discrimination and prejudice) (Latner et al., 2005; Matthews \& Harrington, 2000; McClure, 2009).

\section{Stereotyping, Discrimination, Prejudice, and Stigma}

Stereotypes are collectively agreed upon ideas or notions about particular groups that can be quickly and easily accessed (Hamilton \& Sherman, 1994). Stereotyping occurs when labels link a person to undesirable characteristics (Goffman, 1963), and discrimination occurs when a non-labelled person labels and stereotypes another (Link \& Phelan, 2001). Prejudice has been defined as "an aversive or hostile attitude toward a person who belongs to a group, simply because he [or she] belongs to that group, and is therefore presumed to have the objectionable qualities ascribed to the group" (p. 7, Allport, 1958). Stigma has been defined as "an attribute that links a person to an undesirable stereotype, leading other people to reduce the bearer from a whole and usual person to a tainted, discounted one" (p. 11, Goffman, 1963). These definitions of stigma and prejudice show similarities with regard to discrimination and differential treatment of individuals or groups (Stuber, Meyer \& Link, 2008). Stuber et al. claim that the differences in the definitions of stigma and prejudice relate more to the subjects being studied in each condition, rather than to the definitions of stigma and prejudice per se. They suggested that stigmatised individuals generally have "unusual" conditions afflicting them (mental illness, facial disfigurement and HIV), whereas prejudice incorporates class, race, age and gender divisions.

When extrapolating from Stuber et al.'s (2008) comments, stigma may be directed toward individuals with visible markers of brain injury (e.g.; scars), 
whereas prejudice may be aimed at a specific group, for example adolescents, as a result of stereotyping. This implies that some groups or individuals experience compounding effects of both stigma and prejudice, but for different reasons.

Stigma and its associated aspects (exclusion, discrimination, labelling and stereotyping) have negative emotional and psychological consequences for the stigmatised. For example, higher perceived levels of stigma are associated with low self-esteem in people with mental illness (Link, Struening, Neese-Todd, Asmussen \& Phelan, 2001). Link et al. speculate that this relationship is due to mentally ill patients believing, prior to their illness, that mentally ill people are rejected and devalued and fear that the same will now happen to them. It is possible that this fear of rejection occurs for individuals with brain injuries as well, and, to prevent this from occurring they choose not to disclose their injury when there are no visible markers of injury.

For survivors of brain injury, the belief that others would stereotype and stigmatise them could extend into a wide variety of personal and social situations resulting in non-disclosure of their injury and potentially negative consequences (no consideration, empathy or assistance for their needs and symptoms). When the individual with a brain injury is an adolescent they may have to contend with two fears: the fear of public stigma and discrimination associated with their injury and the fear of being judged by their peers regarding their appearance and behaviour. Furthermore, Miller and Sammons (1999) suggest that other people's negative attitudes and behaviours impact on a disabled person's life as much, or more, than their disability.

As a result of these expectations of prejudice and discriminatory practices if people learn of their disability, individuals with no visible markers of brain injury 
may be motivated to not disclose their injury. When they choose to not disclose their injury, it is likely that the public make judgements about particular behaviour based on stereotypes, (Miller \& Sammons, 1999) the salience of stimuli (Fiske et al., 1982) and information that is easily recalled (Tversky \& Kahneman, 1974).

To examine the impact of informing and not informing people about an adolescent's brain injury, the current research examines whether providing information about an adolescent's brain injury or not providing information about the injury influences the public's attributions for the adolescent's undesirable behaviours. This is examined because information regarding the presence of a brain injury is not necessarily offered by adolescents with these conditions in everyday life. This may be due to fears of being stigmatised or discriminated against, or more simply, a desire to make new acquaintances without having their illness or disability taking centre stage. Adolescents in particular may choose to not disclose this information because they want to "fit in" with their peers. For this reason, it is useful to investigate participants' attributions of undesirable behaviour using conditions which provide information about a brain injury as well as conditions that provide no information about the injury.

\section{Responsibility and Attribution Theory}

Other factors may have influenced McClure et al.'s (2006; 2008) findings. It is possible that participants assigned some responsibility for the cause of the brain injury to the adolescent because they were not advised about the cause of the injury, which then influenced their attributions. Attribution theory contributes to our understanding of discriminatory reactions and responses to individuals with stigmatising conditions. Weiner's attribution theory proposes that individuals make cognitive appraisals regarding the cause and controllability of a person's 
stigmatising condition resulting in judgements of responsibility (Corrigan, Markowitz, Watson, Rowan \& Kubiak, 2003; Weiner, 1995, 2006). These perceptions of responsibility elicit emotional responses, such as anger and sympathy, which subsequently influence people's willingness to help or interact with individuals who have been stigmatised (Weiner, 1995). The controllability of a stigma refers to whether the stigmatising condition is under a person's control or not. Internal causes (mental illness due to illegal drug use) elicit higher judgements of responsibility and external causes (mental illness due to genetics) elicit lower judgements of responsibility. To summarise, people identify the perceived cause of an individual's stigmatising condition and make judgements about internal or external responsibility, which in turn influence people's affective reactions and subsequent behavioural responses towards individuals with stigmatising conditions (Weiner, Perry \& Magnusson, 1988).

Substantial support has been found for Weiner's attribution model applied to stigmatising conditions. Weiner et al. (1988) manipulated the controllability of stigmatising conditions (AIDs, child abuse, obesity, Alzheimers disease, blindness, cancer, heart disease, paraplegia and Vietnam War Syndrome) and found that when participants (university students) were informed that the cause of a condition was controllable, blame and anger increased and pity and liking decreased. The desire to personally assist and give charitable donations also decreased when participants were informed that the onset of the condition was controllable. Consistent with Weiner et al.'s findings, Martin, Pescosolido and Tuch (2000) found that adults were more willing to interact with individuals with mental illness when the cause of the mental illness was attributed to biological or structural causes, rather than to drug and alcohol related causes. These findings mirror research on racial prejudice, 
which found that whites who attribute racial inequality to educational disadvantage and discriminatory policies (external causes as opposed to internal causes) were more likely to support policies which reduced the disadvantages of blacks (Tuch \& Hughes, 1996).

Further support for Weiner's (1995) attribution theory was found by Redpath and associates who examined prejudice and brain injury. Redpath and Linden (2004) found that participants reported less prejudice towards survivors of brain injury and greater willingness to interact and assist when the cause of the injury was external, than when the cause was internal. Linden, Hanna and Redpath (2007) found that the public (mean age of 30 years) reported higher prejudice than psychology students. Furthermore, higher prejudice was reported when individuals were blamed for their injury and males reported higher prejudice and were less inclined to want to socially interact with individuals with brain injury than females. However these studies do not differentiate between individuals with visible or nonvisible brain injuries. The current research examines whether manipulating the visibility of a brain injury and the cause of a brain injury (as a result of a brain tumour, abusing illegal drugs or not identified) influences people's attributions of an adolescent's undesirable behaviour to either their adolescence or their brain injury.

\section{Familiarity with Individuals with Brain Injury}

Another factor which is likely to influence people's attributions of an adolescent's undesirable behaviour is how familiar they are with individuals with brain injury. Previous research shows that familiarity with individuals with mental illness influences participants' reactions and behaviours towards people with mental illness (Corrigan et al., 2003). Holmes, Corrigan, Williams, Canar and 
Kubiak (1999) define familiarity as the amount of contact with and the amount of knowledge of an illness. Corrigan et al. (2003) found that familiarity (measured by contact) with mental illness reduced discriminatory responses. In addition, Corrigan, Green, Lundin, Kubiak and Penn (2001) found that less stigma and discrimination (social distance and dangerousness) was reported when participants were more familiar with individuals with mental illness. Furthermore, more familiarity resulted in less endorsement of prejudice attitudes (both authoritarian and benevolent) (Corrigan, Edwards, Green, Diwan \& Penn, 2001). However, adolescents showed the opposite effect; more familiarity resulted in the likelihood of endorsing stigmas (Corrigan et al., 2005).

The literature examining familiarity with individuals with brain injuries and discrimination is sparse, although Linden et al. (2007) found that familiarity with individuals with brain injury had no effect on reported social interactions and prejudicial attitudes. However, Linden et al. did not report how familiarity was measured and whether the results applied to all participants, or only the students, or only the public.

Based on the mental illness literature, it is possible that the level of familiarity that people have with brain injury and the amount of contact people have had with individuals with brain injury may influence their reactions and behaviours towards individuals with brain injury. The current research examines whether the level of familiarity (measured by contact) with individuals with brain injury relates to attributions for an adolescent's undesirable behaviours to his brain injury or his adolescence. 


\section{The Current Research}

Expanding on previous research (McClure et al., 2006; 2008), the current research examined people's attributions for the undesirable behaviour of a male adolescent with a brain injury. As in previous studies, visible markers of injury (scar or no scar) were manipulated to ascertain whether having visual markers of injury or not having visual markers of injury influenced participants' attributions for an adolescent's undesirable behaviour.

There were three novel aspects to the current research. First, Experiment 1 examined whether providing information or not providing information about an adolescent's brain injury would influence participants' attributions for the adolescent's undesirable behaviours to his brain injury or his adolescence. Second, Experiment 2 examined the effects of manipulating the putative cause of the brain injury (as a result of a brain tumour, abusing illegal drugs or not identified) to ascertain whether organic and self-initiated causes of brain injury would influence participants' attributions. Third, Experiment 2 also examined the effects of familiarity with brain injury, to ascertain whether participants' familiarity with individuals with brain injury relates to their attributions.

\section{Experiment 1}

Experiment 1 extended previous research by McClure et al. (2006; 2008) and examined whether providing information about an adolescent's brain injury would influence participants' attributions for the adolescent's undesirable behaviour to his brain injury and/or a medical condition or his adolescence. This design allowed the comparison of a control group, who were not informed that the adolescent had sustained a brain injury, with a group who were informed that the adolescent had suffered a brain injury. This design also examined participants' 
responses under everyday conditions, where people are not generally informed about an adolescent's medical condition.

It was predicted that participants given no information about the brain injury would attribute the undesirable behaviours more to adolescence than brain injury in both the scar and no scar conditions. In contrast, when given information about the brain injury, participants would attribute the behaviours equally to brain injury and adolescence in the scar condition and more to adolescence than brain injury in the no scar condition, as previously found by McClure et al. (2006; 2008).

To summarize, Experiment 1 examined visibility effects (scar and no scar) and whether providing information about an adolescent's brain injury influences participants' attribution of four behaviours (lacks motivation, sleeps a lot, angers quickly and lacks self-confidence) to either brain injury and/or a medical condition or to his adolescence.

\section{Method}

\section{Participants.}

Ninety eight participants were canvassed locally from Porirua Mall ( $N=$ 11), Manners Mall in Wellington $(N=41)$, Victoria University $(N=20)$ and sports facilities (basketball, netball and flipperball, $N=26$ ). There were 38 males and 60 females ranging in age from 18 to over 60 years old, with 18 participants in the under 20 age bracket, 33 participants in the 20-29 age bracket, 15 participants in the 30-39 bracket, 21 in the 40-49 bracket, 9 in the 50-59 bracket and two in the over 60 bracket. The median age was in the 20-29 age bracket. 


\title{
Materials.
}

A short vignette with a picture of an adolescent boy was shown to each participant. There were two variations to these materials; the photo showed either a scar on his head or no scar (see Appendix A) and the vignette included either information regarding a head injury or no information regarding a head injury. Thus the four conditions were: no scar and no information given, no scar and information given, scar and no information given and scar and information given. The vignette read as follows for the information condition (although the italicised words were not in italics) and the italicised words were deleted for the no information conditions:

\begin{abstract}
Above is a photo of Chris. Chris lives in Wellington and has been going to school, where his favourite class is social studies as he enjoys learning about other cultures as well as New Zealand's culture and bits about history. He would like to become a historian when he gets older, as they get to travel around to different countries and find out about their histories. Chris has suffered from a head injury, which has injured his brain at the time of becoming an adolescent. Since the injury, Chris' parents have noticed some changes in his behaviour that they are a little concerned about. He lacks self-confidence, whereas previously he was more sure of himself. They've also noticed that where Chris used to be quite a calm person, he now appears to anger quickly. Chris appears to be lacking motivation for things he always wanted to do. Chris' parents have also noticed that he now sleeps a lot, often sleeping in and then nodding off again in the afternoon.
\end{abstract}

Participants indicated on seven point Likert scales how likely adolescence and head injury and/or some other medical condition were as an explanation for each of the four behaviours (sleeps a lot, angers quickly, lacks self-confidence and lacks motivation). This measure was the measure used by McClure et al. (2006; 2008). The Likert scale ranged from 1 'very poor explanation' to 7 'very good 
explanation', with 4 indicating neither good nor poor explanation for the behaviour described. The four behaviours were previously identified by McClure et al. (2006) as typical of adolescents and individuals with brain injury. Participants also indicated their age and gender.

\section{Procedure.}

Ethics approval was granted by Victoria University of Wellington Ethics Committee. Participants were canvassed at the sites mentioned above and asked if they had five minutes to complete a questionnaire and were randomly assigned to one of the four conditions. This sample pool was used to provide a broader pool than solely students, as used in previous studies using this paradigm (McClure et al., 2006; 2008). Randomisation was accomplished by placing the questionnaire for each condition in a separate folder. Once a participant completed a questionnaire that folder was placed to the back of the group of folders and the front folder was selected for the next participant. This procedure was carried out at each data collection. The sample size chosen was selected to ensure a minimum of 20 participants in each condition. Participants were advised the research was for my Masters thesis at Victoria University and involved answering questions regarding adolescent behaviours. They were also informed that they could withdraw from the research at any point prior to handing in the completed questionnaire. Participants read the vignette and viewed the photograph, then completed the questionnaire. They were advised the survey was voluntary and anonymous and asked not to write their names on the forms; a chocolate was given as a thank you. Once they had completed the questionnaire, participants were debriefed and told that the boy in the photo had not suffered a head injury and 
asked if they would like to receive the results of the research. Email addresses were recorded if they requested further information.

\section{Results}

A 2 (Attribution: medical condition and/or brain injury or adolescence) x 2 (Photo: scar or no scar) x 2 (Information: no information given or information given) x 4 (Behaviour: sleeps a lot, angers quickly, lacks self-confidence and lacks motivation) mixed design MANOVA was conducted. MANOVAs are robust against violations of homogeneity. There was a significant main effect for Behaviour, $F(3,92)=2.89, p<.05, \eta^{2}=.09$, with sleeps a lot rated highest $(M=$ 4.35), then lacks self-confidence $(M=4.24)$, followed by angers quickly $(M=4.21)$ and lacks motivation $(M=4.09)$. There was a significant main effect for Attribution, $F(1,94)=9.51, p<.01, \eta^{2}=.09$, with higher attributions to adolescence $(M=4.54)$ than brain injury and/or some other medical condition $(M=$ $3.90)$. 


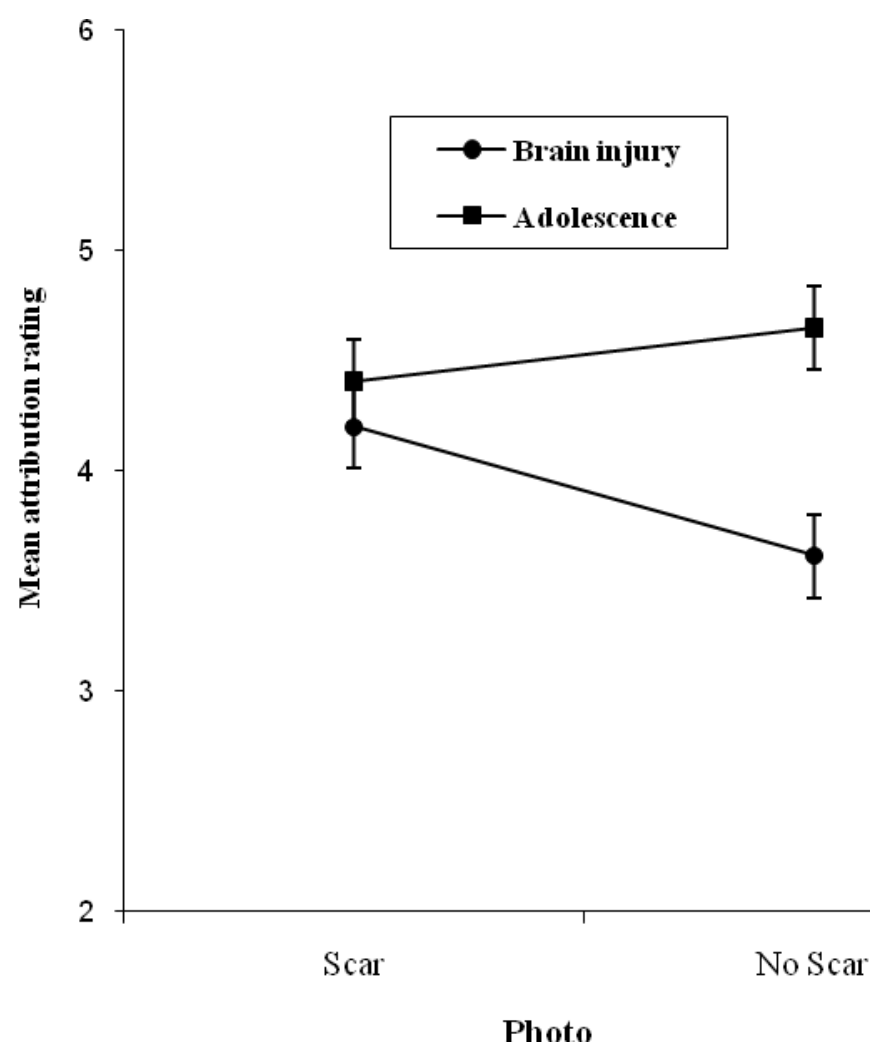

Figure 1: Two way interaction between Attribution (brain injury and/or some other medical condition or adolescence) and Photo (scar or no scar). Standard error bars are also shown and are shown in all subsequent figures.

As predicted, there was a two way interaction between Attribution and Photo, $F(1,94)=4.22, p<.05, \eta^{2}=.04($ see Figure 1$)$. The interaction between Attribution and Photo was qualified by a three way interaction between Behaviour, Attribution and Photo, $F(3,92)=2.91, p<.05, \eta^{2}=.09$. Figure 2 shows the mean attribution ratings in the scar condition and Figure 3 shows the mean attribution ratings in the no scar condition. To clarify the interaction, 2 (Attribution) $\mathrm{x} 4$ (Behaviour) ANOVAs were performed separately for the scar and no scar conditions. In the no scar condition, there was a significant main effect for Attribution, $F(1,48)=8.75, p<.01, \eta^{2}=.15$, with higher attributions to adolescence $(M=4.69)$ than brain injury and/or some other medical condition $(M=$ 3.60). There was no interaction between Attribution and Behaviour, $F(3,46)=$ 
$1.21, p>.05, \eta^{2}=.07$. In the scar condition there was no main effect for attribution, $F(1,48)=0.58, p>.05, \eta^{2}=.01$, but there was an interaction between Attribution and Behaviour, $F(1,46)=3.21, p<.05, \eta^{2}=.17$. To clarify the interaction, paired samples $t$-tests were conducted for each of the four behaviours, comparing attributions to adolescence and attributions to brain injury and/or some other medical condition. There was a significant difference for lacks motivation, with higher attributions to adolescence $(M=4.53)$ than brain injury and/or some other medical condition $(M=3.71), t(48)=-2.40, p<.05$. There was no difference in the attributions for the other three behaviours, sleeps a lot, $t(48)=-.53, p>.05$, lacks self confidence, $t(48)=.12, p>.05$, and angers quickly, $t(48)=.24, p>.05$. 


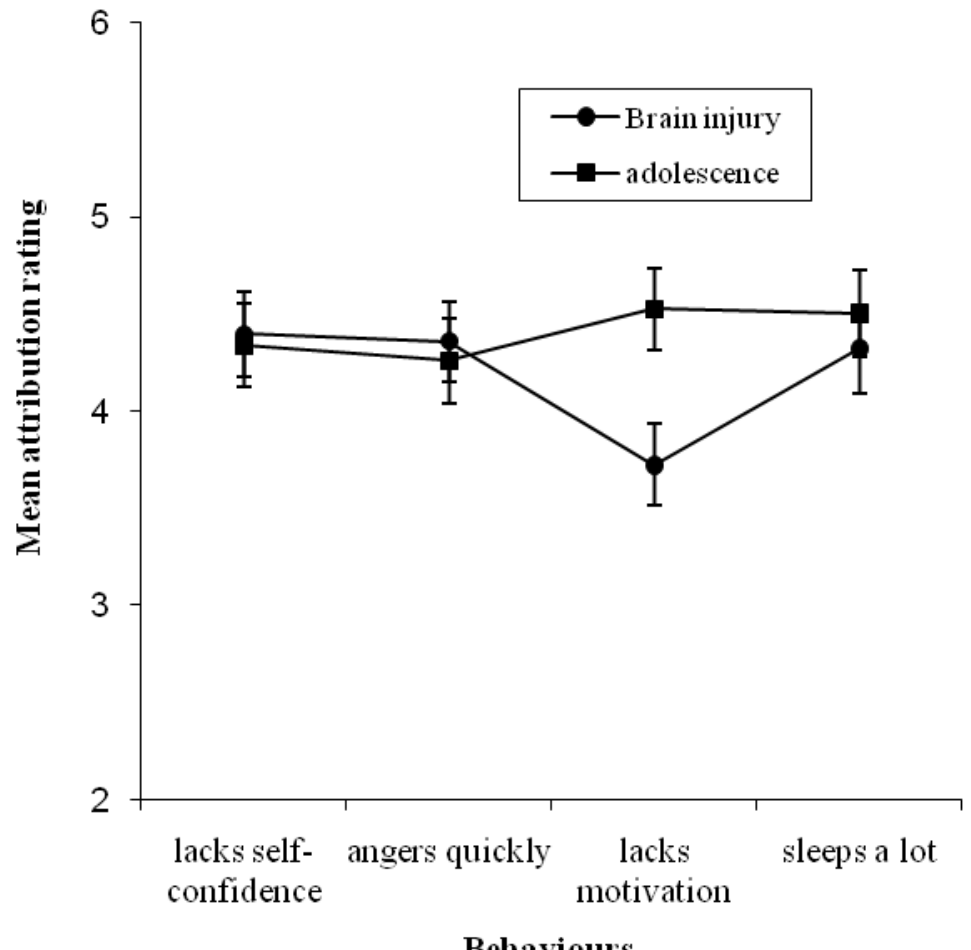

Behaviours

Figure 2: Mean attribution rating of behaviours to brain injury and/or some other medical condition and adolescence in the scar Photo condition.

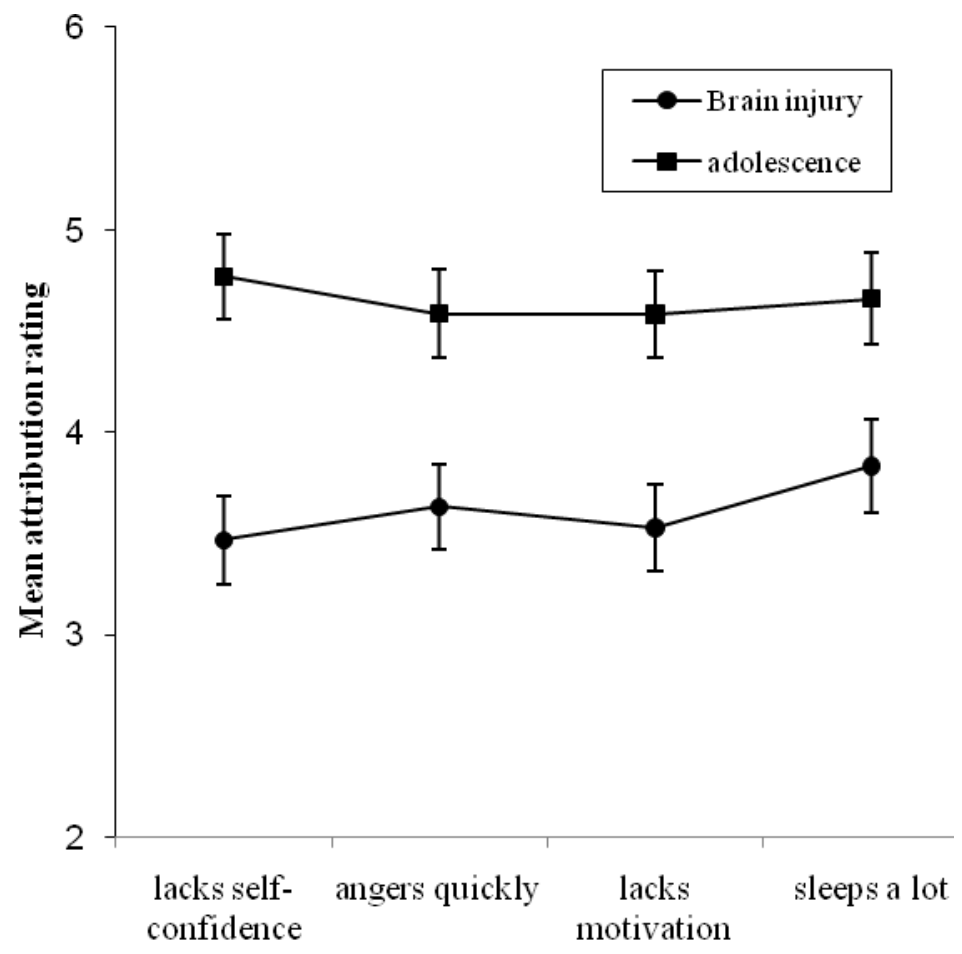

\section{Behaviours}

Figure 3: Mean attribution rating of behaviours to brain injury and/or some other medical condition and adolescence in the no scar Photo condition. 
There was a two way interaction between Attribution and Information, $F(1$, $94)=32.81, p<.001, \eta^{2}=.26$ (see Figure 4). To clarify this interaction, a 2 (Attribution) x 4 (Behaviour) ANOVA was conducted for the information and no information conditions separately. As predicted, in the no information condition attributions were higher to adolescence $(M=4.99)$ than brain injury and/or some other medical condition $(M=3.22), F(1,49)=45.26, p<.001, \eta^{2}=.48$, whereas in the information condition there was no difference between attributions to adolescence $(M=4.07)$ and brain injury and/or some other medical condition $(M=$ 4.60), $F(1,47)=1.22, p>.05, \eta^{2}=.08$.

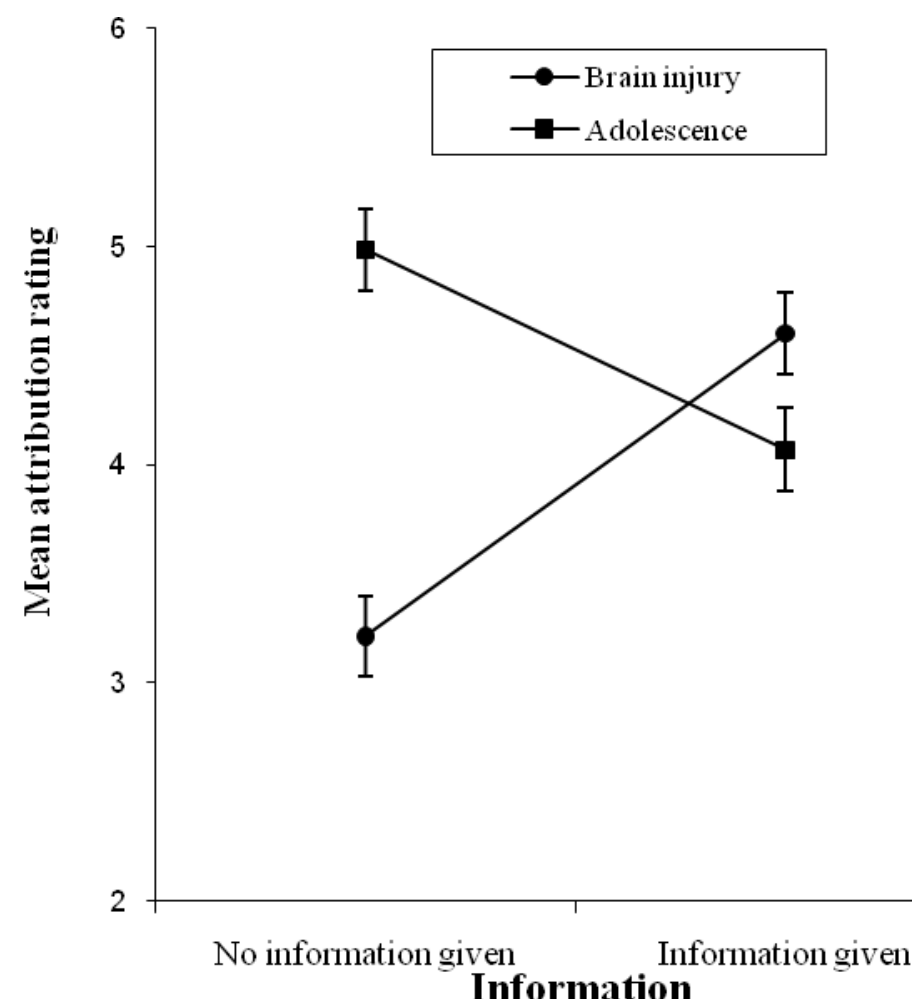

Figure 4: Two way interaction between Attribution (brain injury and/or some other medical condition or adolescence) and Information (information given or no information given).

A further two way interaction, which was not relevant to the hypothesis, was between attribution and behaviour, $F(3,92)=3.12, p<.05, \eta^{2}=.09$. 


\section{Discussion}

It was predicted that participants given no information about an adolescent's brain injury would attribute the undesirable behaviours more to adolescence than brain injury and/or some other medical condition in both the scar and no scar conditions. Hereafter, attributions to brain injury and/or some other medical condition in Experiment 1 are referred to as attributions to brain injury. In contrast, when given information about the brain injury, participants would attribute the behaviours equally to brain injury and adolescence in the scar condition and more to adolescence than brain injury in the no scar condition. Overall, the predictions were supported.

As expected, when participants were advised about the adolescent's brain injury, the undesirable behaviours were attributed more to adolescence than brain injury when there were no visible markers of injury. When there were visible markers of injury, participants attributed the behaviours equally to adolescence and brain injury, as previously found by McClure et al. (2006; 2008). However, a three way interaction between Behaviour, Attribution and Photo prompted further analysis. Participants attributed the behaviour lacks motivation more to adolescence than brain injury in both the scar and no scar conditions (as also found by McClure et al., 2006; 2008). These results support the notion that adolescent males with no visible signs of brain injury have less emphasis placed on their injury, relative to their life stage (adolescence), when people attribute causes for their undesirable behaviour. The results also imply that male adolescents with no visible markers of brain injury have their injury discounted as an explanation for socially undesirable behaviour (McClure et al., 2008). 
As expected, when participants were not advised about the adolescent's brain injury they attributed the undesirable behaviours more to adolescence than brain injury in both the scar and no scar conditions. This finding suggests that when participants are not informed about an adolescent's brain injury visible markers of injury do not override the salience of adolescence, resulting in less allowance for the brain injury as a cause of the undesirable behaviours. Experiment 1 also shows that visible markers of injury do influence attributions when participants are informed about a brain injury but they do not influence attributions when participants are not informed about an injury.

There are other factors which potentially influence people's attributions of adolescents' undesirable behaviour, such as whether they judge the adolescent as responsible for their brain injury and how familiar people are with individuals with brain injury. These issues are examined in Experiment 2.

\section{Experiment 2}

It is possible that participants in McClure et al.'s (2006: 2008) research attributed the undesirable behaviours equally to adolescence and brain injury in the scar condition and more to adolescence than brain injury in the no scar condition because they made judgements about the cause of the adolescent's brain injury. Causation is an important aspect of Weiner's attribution theory; people attempt to identify the cause of an illness to ascertain whether the person was in control and therefore responsible (Weiner, 1995). When participants are advised that the cause of an adolescent's brain injury was external (caused by a brain tumour), they are likely to attribute the undesirable behaviours more to the brain injury sustained, than adolescence. 
Experiment 2 examined this issue and manipulated the stated cause of the brain injury in the scenario. It was predicted that when participants were informed that the adolescent was not responsible for their injury (as a result of a brain tumour) they would attribute the undesirable behaviours more to the brain injury than adolescence in the scar condition, and equally to adolescence and brain injury in the no scar condition. In contrast, when informed that the adolescent was responsible for their injury (as a result of abusing illegal drugs), participants would attribute the behaviours more to adolescence than brain injury in both the scar and no scar conditions. When the cause of the brain injury was not identified, it was predicted that participants would attribute the behaviours equally to adolescence and brain injury in the scar condition and more to adolescence than brain injury in the no scar condition. This was predicted on the grounds that Corrigan et al. (2003) found that participants showed less anger and fear and more pity when informed that a mentally ill person was not responsible for their illness than when they were not so informed. Similarly, Redpath and Linden (2004) found that participants reported less prejudice towards survivors of brain injury, as well as greater willingness to interact and assist when the cause of the injury was external.

Participants' level of familiarity with individuals with brain injury was also examined in Experiment 2 because their familiarity is likely to influence their attributions for the adolescent's undesirable behaviour. Also, participants who have had more contact with individuals with brain injury may be more aware of the subsequent behavioural problems experienced by survivors of brain injury, than participants with less familiarity.

It was predicted that participants more familiar with individuals with brain injury would attribute the undesirable behaviours more to brain injury than 
participants with low familiar with individuals with brain injury, in both scar conditions. In contrast, participants with low familiarity would attribute the behaviours more to adolescence than participants with high familiarity, in both scar conditions. These predictions are based on Corrigan, Edwards, Green, Diwan and Penn's (2001) findings that more familiarity resulted in less stigma toward the mentally ill.

To summarise, Experiment 2 examined visibility effects (scar and no scar) and whether the cause (as a result of a brain tumour or resulting from abusing illegal drugs or not identified) of a brain injury influences participants' attributions for an adolescent's undesirable behaviours (lacks motivation, sleeps a lot, angers quickly and lacks self-confidence) to either his brain injury or his adolescence. It also examined whether familiarity with individuals with brain injury influenced participants' attributions for the adolescent's undesirable behaviours.

\section{Method}

\section{Participants.}

One hundred and forty eight participants were approached in Wellington central business district in either Manners Mall $(N=95)$, Midland Park $(N=41)$ or the waterfront $(N=11)$. There were 72 males and 75 females ranging in age from 18 to over 60 years old, with 10 participants aged under 20, 60 aged 20-29, 29 aged 30-39, 24 aged 40-49, 16 aged 50-59 and 8 aged over 60. The median age was in the 30-39 age bracket.

\section{Materials.}

A short vignette with a picture of an adolescent boy called Chris, who had suffered a brain injury, was shown to each participant. The photo showed either a 
scar or no scar on the adolescent's head (see Appendix A). There were three variations to the vignette describing the adolescent boy. The vignette was identical to Experiment 1 in the first condition which gave no details regarding how Chris acquired his brain injury (not identified). The second condition described an organic cause for his brain injury (resulting from a brain tumour), implying the adolescent was not responsible and the third condition described a self-initiated cause (as a result of abusing illegal drugs), implying the adolescent was responsible. Thus the six conditions were: no scar and the cause of the brain injury was not identified, no scar and information implying no responsibility, no scar and information implying responsibility, scar and no details regarding responsibility, scar and information implying no responsibility, scar and information implying responsibility. In the self-initiated conditions the words, "as a result of abusing illegal drugs", were added after the words "Chris has suffered from a head injury" and in the organic condition the words, "as a result of a brain tumour", were added after the words "Chris has suffered from a head injury".

As in Experiment 1, participants indicated on seven point Likert scales how likely adolescence and head injury were as an explanation for each of the four behaviours (sleeps a lot, angers quickly, lacks self-confidence and lacks motivation). The head injury attribution in Experiment 2 made no reference to a medical condition as in Experiment 1, because there was no need for this, as all vignettes in Experiment 2 described Chris' brain injury. In addition to these questions, there were a further three questions that participants rated on seven point Likert scales. The questions read: "From the information you have about Chris, how severe do you think Chris' head injury probably was?", "From the information you have about Chris, how controllable, do you think, is the cause of 
Chris' present condition?" and "From the information you have about Chris, how responsible, do you think, is Chris for his present condition?". Participants were also asked how familiar they were with people with brain injury and circled a number from 1 to 8 next to statements about familiarity. Statements included: "I have never observed a person with brain injury" and "I live with a person with a severe brain injury. Appendix B shows the Likert scales and wording used for the eight statements. The familiarity scale was adapted from Holmes, Corrigan, Williams, Canar and Kubiak (1999). As a measure of reliability, three psychiatric experts rated the items with regards to degrees of intimacy of contact; the interrater reliability between them was an acceptable level at .83 . Details regarding age and gender were also recorded.

\section{Procedure.}

The procedure was identical to Experiment 1 except that participants were randomly assigned to one of six conditions and approached in the locations mentioned above. No university students were canvassed in Experiment 2.

\section{Results}

\section{Effects of Different Causes of Brain Injury.}

A 2 (Attribution: brain injury or adolescence) x 2 (Photo: scar or no scar) x 3 (Cause: brain tumour, abusing illegal drugs or not identified) x 4 (Behaviour: sleeps a lot, angers quickly, lacks self-confidence and lacks motivation) mixed design MANOVA was conducted. There was a significant main effect for Behaviour, $F(3,139)=4.32, p<.01, \eta^{2}=.09$, with angers quickly rated highest $(M$ $=4.63)$, then sleeps a lot and lacks self-confidence both rated $(M=4.55)$, followed by lacks motivation $(M=4.39)$. 
There was a three way interaction between Attribution, Cause and Photo, $F(2,141)=5.25, p<.01, \eta^{2}=.07$. Figure 5 shows the means in the scar Photo condition for the three way interaction and Figure 6 shows the means in the no scar Photo condition. 


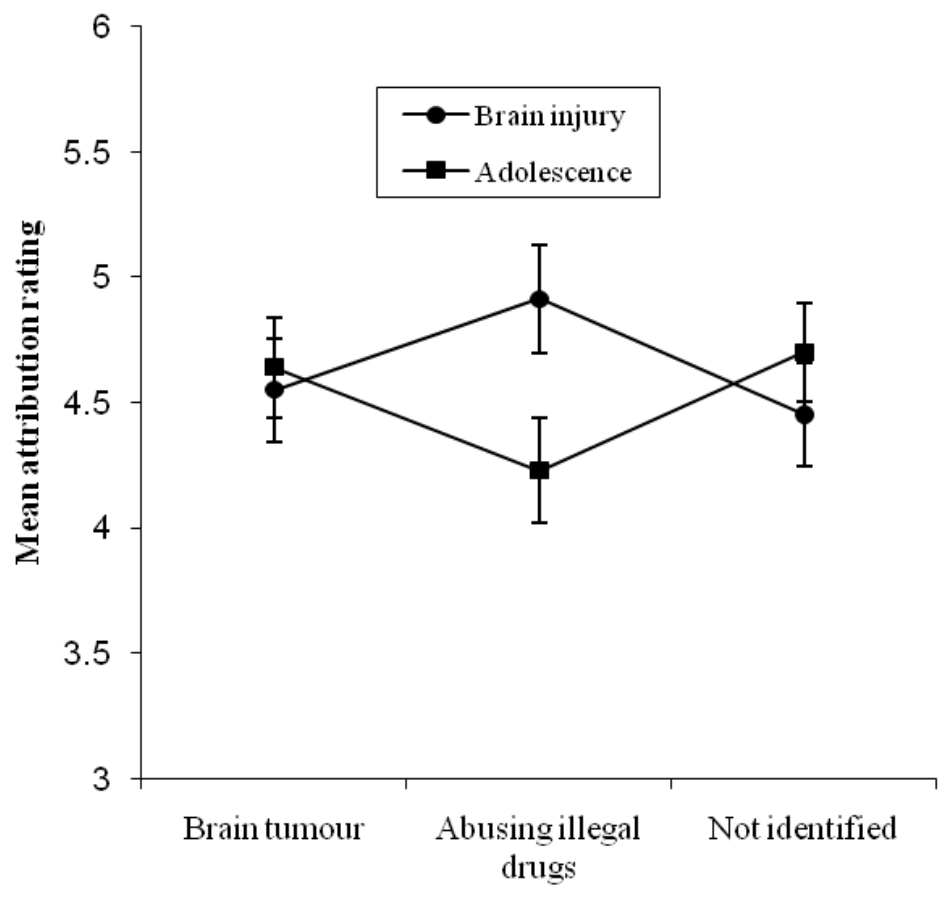

Causes of Brain Injury - Scar Photo Condition

Figure 5. Mean attributions (brain injury or adolescence) for the three causes of injury conditions (brain tumour, abusing illegal drugs or not identified) for the scar Photo condition.

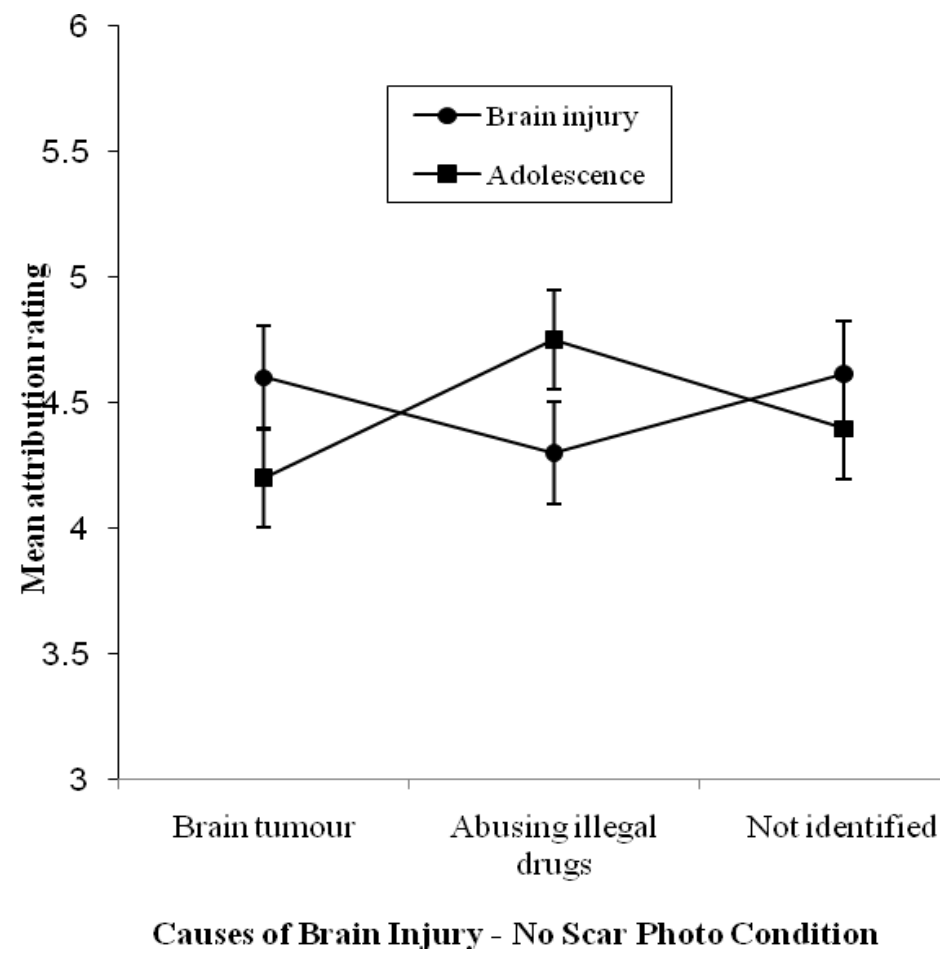

Figure 6. Mean attributions (brain injury or adolescence) for the three causes of injury conditions (brain tumour, abusing illegal drugs or not identified) for the no scar Photo condition. 
To clarify this three way interaction, 2 (Attribution) x 2 (Photo) ANOVAs were conducted separately for each Cause (brain tumour, abusing illegal drugs and not identified). Two composite variables were created (one averaging the attributions to brain injury and one averaging the attributions to adolescence) and used as dependent variables. In the 'abusing illegal drugs' condition there was an interaction between Attribution and Photo, $F(1,46)=9.80, p<.01, \eta^{2}=.18$, as shown in Figure 7. Additional analyses were conducted for the 'abusing illegal drug' condition. Select cases and split file were used to select only the 'abusing illegal drug' data and report the scar and no scar data separately. A MANOVA was conducted using the two new composite variables (mean attributions to brain injury and mean attributions to adolescence) as dependent variables. In the no scar condition, participants attributed the undesirable behaviour more to adolescence ( $M$ $=4.75)$ than brain injury $(M=4.30), F(1,24)=5.25, p<.05, \eta^{2}=.18$, whereas in the scar condition participants attributed the behaviours more to brain injury $(M=$ 4.91) than adolescence $(M=4.23), F(1,22)=4.82, p<.05, \eta^{2}=.18$. There was no significant main effect for Attribution, $F(1,46)=.42, p>.05, \eta^{2}=.01$, for the 'abusing illegal drugs' condition. 


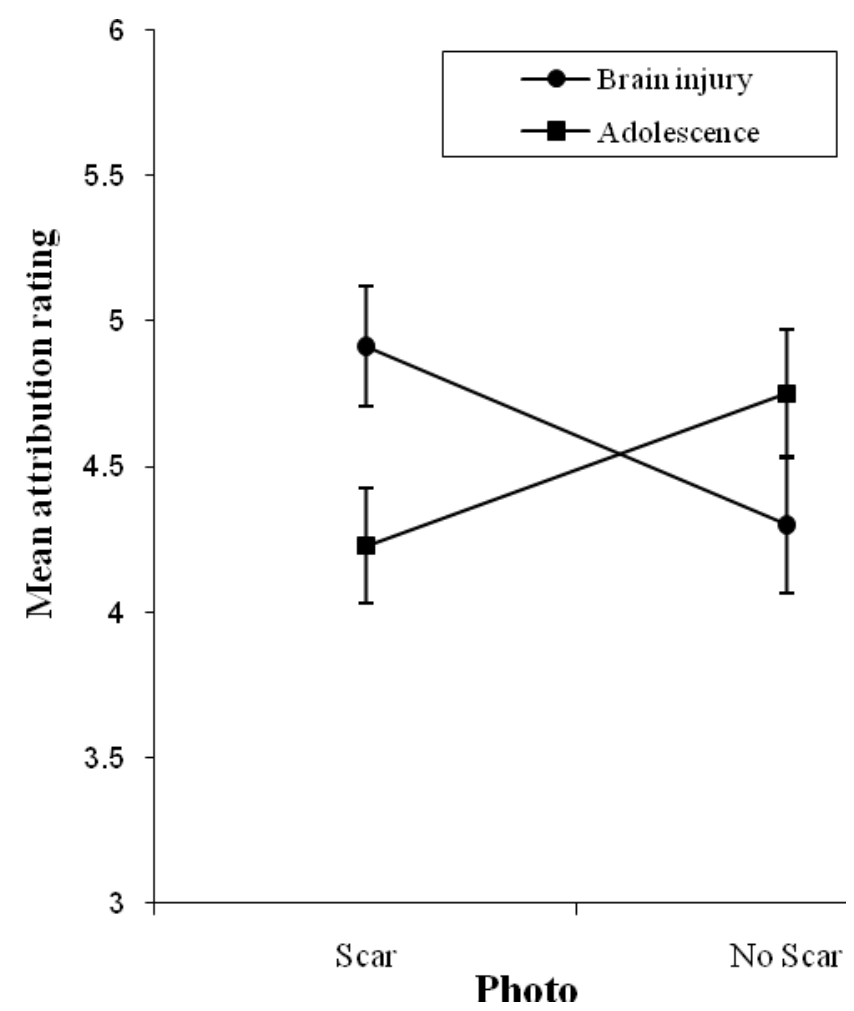

Figure 7. Mean attribution rating to brain injury and adolescence in the scar and no scar Photo conditions for the 'abusing illegal drugs' condition.

For the 'brain tumour' condition there was no significant main effect, $F(1,48)=$ $.65, p>.05, \eta^{2}=.01$ or interaction, $F(1,48)=1.63, p>.05, \eta^{2}=.03$. Similarly, for the 'not identified' condition there was no significant main effect for Attribution, $F(1,47)=005, p>.05, \eta^{2}=.00$, or interaction between Attribution and Photo, $F(1$, 47) $=1.04, p>.05, \eta^{2}=.02$.

To examine whether the Photo and Cause conditions had an impact on 'responsibility' (whether participants thought Chris was responsible or not for his current condition), a 2 (Photo: scar or no scar) by 3 (Cause: brain tumour, abusing illegal drugs or not identified) ANOVA was conducted on ratings of responsibility. As shown in Figure 8 there was a significant main effect for Cause, $F(2,146)=$ $19.18, p<.001, \eta^{2}=.22$. Participants assigned more responsibility to 'abusing 
illegal drugs' $(M=4.64)$, than 'brain tumour' $(M=3.09)$ and 'not identified' $(M=$ 3.24). There were no other significant effects.

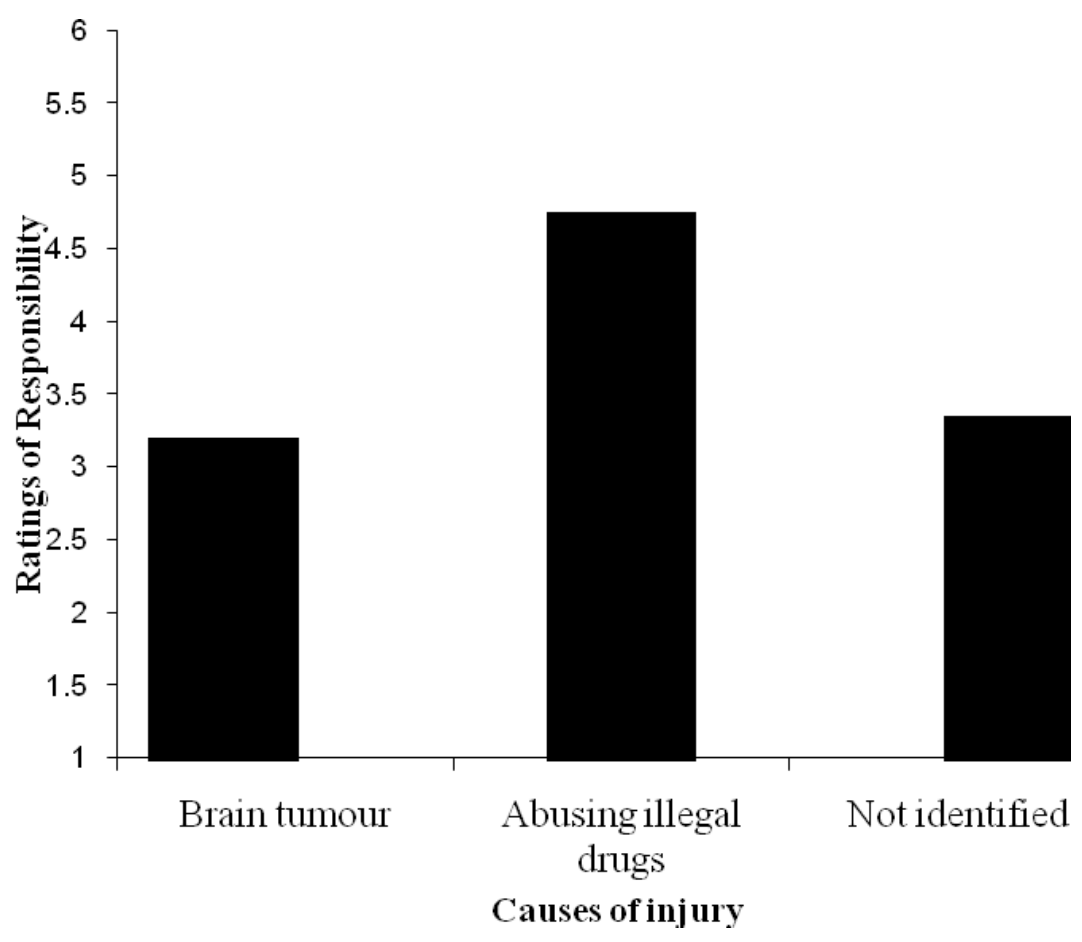

Figure 8. Mean attribution rating for 'responsibility' (how responsible participants thought Chris was for his current condition) and the three causes of injury conditions (brain tumour, abusing illegal drugs or cause not identified).

This analysis shows that participants assigned more responsibility to Chris for his current condition when he was described as abusing illegal drugs, as opposed to when he was described as having a brain tumour or when the cause was not identified. Whether there was a scar, or not, did not impact on participants' ratings of assigning responsibility. This analysis also serves as a manipulation check, to check whether participants did actually read the vignette.

\section{Effects of Familiarity.}

A 2 (Attribution: brain injury and/or medical condition or adolescence) x 2 (Photo: scar or no scar) x 8 (Familiarity: 1 - 8) repeated measures MANOVA was conducted using the two composite variables (mean attributions to brain injury and 
mean attributions to adolescence) as dependent variables to examine whether participants' familiarity with individuals with brain injury, relate to their attributions of the injured adolescent's undesirable behaviour. There was a three way interaction between Attribution, Photo and Familiarity, $F(7,131)=2.32, p<$ $.05, \eta^{2}=.11$. Because the Familiarity variable has a large number of categories (8) for a variable in a MANOVA and there were very few participants in some of the familiarity conditions, a dichotomous familiarity variable was created. Items 1 and 2 of the familiarity scale were combined to create a low familiarity condition and items 3 to 8 were combined to create a high familiarity condition because these items all entailed personal contact with the individual (see Table 1). A composite dichotomous familiarity variable was created by subtracting low familiarity from high familiarity; this variable was used in the following analysis.

Table 1

Familiarity Scale: number of participants in each condition

\begin{tabular}{clc}
\hline $\begin{array}{c}\text { Item } \\
\text { Number }\end{array}$ & \multicolumn{1}{c}{ Statement of familiarity } & $\begin{array}{c}\text { Number of } \\
\text { participants }\end{array}$ \\
\hline 1 & I have never observed a person with brain injury & 28 \\
\hline 2 & I have watched a television show that included a & 25 \\
& person with brain injury & 45 \\
\hline 3 & I have observed a person with severe brain injury & 16 \\
\hline 4 & I have been in a class with a person with severe brain & \\
\hline 5 & injury & 21 \\
\hline 6 & A friend of the family has a severe brain injury & 5 \\
\hline 7 & I live with a person with a severe brain injury & 3 \\
\hline 8 & I have a severe brain injury
\end{tabular}


The same analysis as above was performed using the new dichotomous Familiarity variable. This analysis also showed a three way interaction between Attribution, Photo and Familiarity, $F(1,143)=9.55, p<.01, \eta^{2}=.06$. Figure 9 shows the means in the scar Photo condition for the three way interaction and Figure 10 shows the means in the no scar Photo condition. To clarify this three way interaction, 2 (Attribution: brain injury or adolescence) x 2 (Familiarity: high or low) MANOVAs were conducted separately for the scar and no scar Photo conditions. In the scar Photo condition there was a two way interaction between Attribution and Familiarity, $F(1,71)=11.21, p=.001, \eta^{2}=.14$. To clarify the two way interaction, separate ANOVAs were performed on the Mean Attributions to adolescence and Mean Attributions to brain injury for participants in both Familiarity conditions. As expected, participants with high familiarity attributed the undesirable behaviours more to the brain injury $(M=4.82)$ than participants with low familiarity $(M=4.29), F(1,72)=4.71, p<.05, \eta^{2}=.06$. Also as expected, participants with low familiarity attributed the behaviours more to adolescence $(M$ $=4.95)$ than participants with high familiarity $(M=4.30), F(1,72)=9.24, p<.01$, $\eta^{2}=.12$

In the no scar Photo condition there were no significant interactions and no other significant effects. It was expected that in this condition, participants with high familiarity would attribute the undesirable behaviours more to brain injury than participants with low familiarity who would attribute the behaviours more to adolescence. This did not occur; both groups attributed the behaviours equally to brain injury and adolescence. 


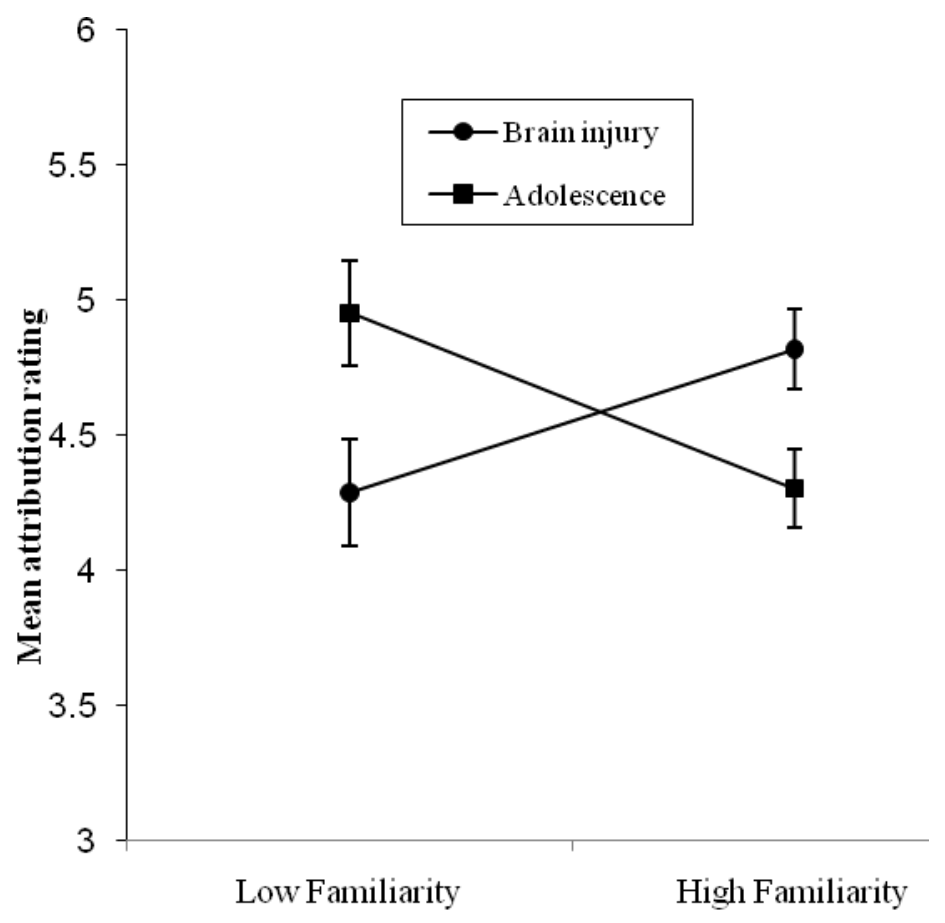

Familiarity with individuals with brain injury Scar Photo condition

Figure 9. Mean attributions (brain injury or adolescence) for individuals with low and high familiarity for the scar Photo condition.

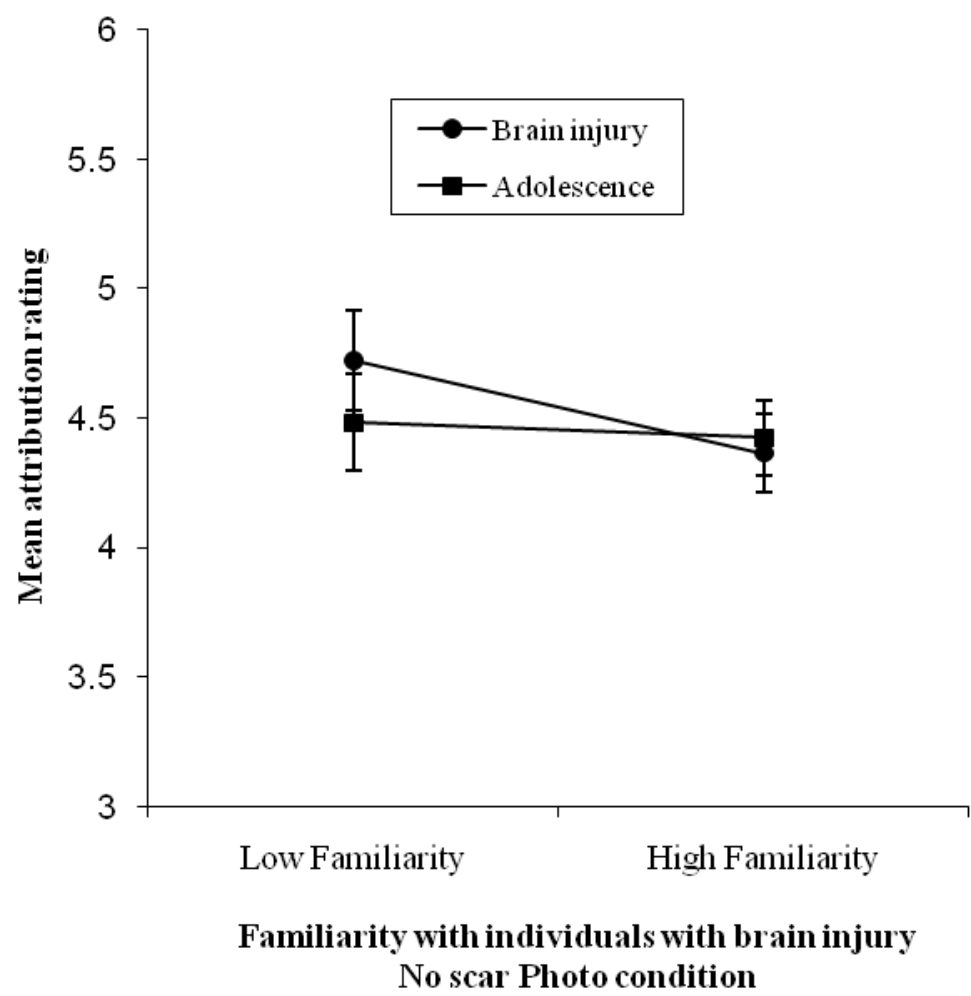

Figure 10. Mean attributions (brain injury or adolescence) for individuals with low and high familiarity for the No scar Photo condition. 


\section{Discussion}

\section{The Effects of Different Causes of Brain Injury.}

It was predicted that participants in the 'brain tumour' condition would attribute the undesirable behaviours more to the brain injury than adolescence in the scar condition and equally to brain injury and adolescence in the no scar condition. In contrast, participants in the 'abusing illegal drugs' condition would attribute the behaviours more to adolescence than brain injury in both scar conditions. It was further expected that participants in the 'not identified' condition would attribute the behaviours more to adolescence than brain injury in the no scar condition and equally to adolescence and brain injury in the scar condition.

Partial support was found for these hypotheses. As predicted, when the cause of the brain injury was a brain tumour, participants attributed the behaviours equally to brain injury and adolescence in the no scar condition and in the scar condition participants also attributed the behaviours equally to the brain injury and adolescence, when it was expected that they would attribute the behaviours more to the injury. As predicted, when the described cause of the brain injury was abusing illegal drugs, in the no scar condition participants attributed the behaviours more to adolescence than the injury, whereas in the scar condition, participants attributed the behaviours more to the injury than adolescence, when the reverse was predicted. Finally, as predicted, when the cause of the brain injury was not identified, participants attributed the behaviours equally to the injury and adolescence in the scar condition and in the no scar condition participants also attributed the behaviours equally to the injury and adolescence, when it was expected that they would attribute the behaviours more to the brain injury. 
A manipulation check suggests that participants did actually read and understand the vignette, as they rated the adolescent as more responsible in the abusing illegal drug condition, relative to the brain tumour condition and the not identified condition.

\section{Effects of Familiarity.}

It was predicted that participants who had more contact with individuals with brain injury would attribute the undesirable behaviours more to the brain injury than participants with low familiarity with individuals with brain injury in both scar conditions, whereas, participants with low familiarity would attribute the behaviours more to adolescence than participants with high familiarity. Partial support was found for these hypotheses. As expected, in the scar condition, participants with high familiarity attributed the behaviours more to the brain injury than participants with low familiarity and participants with low familiarity attributed the behaviours more to adolescence than participants with high familiarity. However, in the no scar condition, participants in both groups attributed the behaviours equally to brain injury and adolescence. The familiarity results suggest that visible markers of injury prompt participants with high familiarity to attribute the undesirable behaviours more to the brain injury and prompt individuals with low familiarity to attribute the behaviours more to adolescence.

\section{General Discussion}

The current research extended previous research (McClure et al., 2006; 2008) by examining the effects of visible markers of brain injury (scar and no scar) combined with three other factors: being informed about the injury, the putative 
cause of injury (resulting from a brain tumour, abusing illegal drugs or cause not identified) and participants' familiarity with individuals with brain injury. These additional factors were examined to identify whether they had an impact on participants' attributions for a male adolescent's undesirable behavior to either his adolescence or his brain injury.

\section{Effects of Providing Information about the Brain Injury}

Experiment 1 manipulated the effects of visible makers of brain injury and providing information about the brain injury. In addition to the information condition used in previous studies, where participants are told that an adolescent has had a brain injury, the "no information" condition was added to more closely resemble real world situations, where people are not necessarily informed about an adolescent's medical condition. Consistent with the hypotheses and previous research (McClure et al., 2006; 2008), participants informed about the adolescent's brain injury attributed his undesirable behaviours more to adolescence than brain injury and/or a medical condition in the no scar condition and equally to adolescence and brain injury and/or a medical condition in the scar condition. Also as predicted, in the novel condition where participants were not informed about the brain injury, they attributed the undesirable behaviours more to adolescence than brain injury and/or a medical condition in both the scar and no scar conditions.

Thus, when participants were not advised about the adolescent's brain injury, they made higher attributions to adolescence even when the photo of the adolescent showed a head scar and they could attribute the behaviours to either the brain injury or adolescence. This suggests that visible markers of brain injury have little or no impact on attributions when people are not informed that the person has a brain injury. In contrast, when participants are informed about the brain injury, 
visible markers of injury do influence attributions (participants attributed the behaviours equally to brain injury and adolescence when there was a scar and more to adolescence than brain injury when there was no scar). One explanation of these findings is that when people are informed about a male adolescent's brain injury and he has no visible markers of brain injury, people discount his brain injury as an explanation for his socially undesirable behaviour (McClure et al., 2008).

The findings of Experiment 1 extend previous research on the effects of visible markers of brain injury by showing that when people are not informed about an adolescent's brain injury, as often occurs in everyday situations, visible markers of injury do not override the salience of adolescence, resulting in less allowance for the brain injury as a cause of the undesirable behaviour. This finding relates to the issue of disclosing or not disclosing a disability. Extrapolating from the results nondisclosure may have the advantages of preventing stigma, but may also have the disadvantages of insufficient care and assistance in alleviating the behaviours that resulted from the brain injury.

\section{Effects of different causes of brain injury}

Experiment 2 manipulated the effects of visible markers of brain injury and the putative cause of the brain injury (resulting from a brain tumour, from abusing illegal drugs or not identified). When the brain injury was described as being caused by a brain tumour, as predicted, participants attributed the behaviours equally to adolescence and the brain injury in the no scar condition. However the same pattern was found in the scar condition, where it was predicted that participants would attribute the behaviours more to the brain injury than adolescence. These results suggest that visible markers of injury have no impact on participants' attributions for an adolescent's undesirable behaviour when the 
described cause is external (caused by a brain tumour) and no responsibility for the brain injury is implied.

A possible reason for the finding in the scar condition is that participants may have assigned some responsibility to the adolescent for their lack of recovery from the brain injury and the vignette only discussed what caused the injury. Participants may have assigned responsibility for recovery because they were told that the adolescent lacked motivation and self-confidence and they may have thought that these behaviours would impede recovery. The belief that recovery is dependent on the effort expended is a common misconception regarding brain injuries (Gouvier et al., 1988).

When the cause of the brain injury was not identified, participants attributed the behaviours equally to adolescence and brain injury in the scar and no scar condition. It was hypothesised that this result would occur only in the scar condition and that participants would attribute the behaviours more to adolescence than brain injury in the no scar condition as also predicted in Experiment 1 . It is possible that participants attributed the behaviours equally to adolescence and brain injury because they judged the injury as occurring through a sporting accident (external cause) as the adolescent in the picture was wearing a rugby shirt. Several participants made this observation after they had completed the questionnaire. This may explain the similar results found in the not identified and brain tumour conditions; in both conditions the causes of injury may have been viewed as external. This explanation is consistent with the finding that participants assigned more responsibility to the adolescent for his brain injury when he was described as abusing illegal drugs, as opposed to when a brain tumour was described and when 
the cause was not identified, irrespective of whether there was a scar or no scar. These results are discussed further in the section on visible markers of injury.

When the cause of the brain injury was described as abusing illegal drugs, as predicted participants attributed the behaviours more to adolescence than brain injury in the no scar condition, whereas they attributed the behaviours more to the brain injury than adolescence in the scar condition when the reverse was predicted. The results suggest that when there are no visible markers of injury and an adolescent is perceived as responsible for their injury, then less allowance is given to the brain injury as a cause of the undesirable behaviour. In contrast, when there are visible markers of injury, more allowance is given to the brain injury as a cause of the undesirable behaviour.

A possible reason for participants attributing the behaviours more to the brain injury than adolescence in the abusing drugs scar condition is that participants in Experiment 2, with a median age in the 30-39 age bracket, may have attributed some responsibility to the adolescent's parents for his current condition as carers and protectors of him. This may not have occurred in the tumour and not identified conditions, as it could be difficult to assign responsibility to parents in these conditions. Also, it is possible that the scar, together with the description of the internal cause (abusing illegal drugs), caused the participants to focus more on the brain injury than the adolescent's life stage.

To summarise, whether there was a scar or no scar had no effect on attributions or responsibility judgements in conditions describing a brain tumour or not identifying the cause of the brain injury, but visible markers of injury did have an effect when the described cause was abusing illegal drugs. In this condition, 
participants attributed the behaviours more to adolescence than brain injury in the no scar condition and more to brain injury than adolescence in the scar condition.

\section{Effects of familiarity}

Experiment 2 also examined whether participants' familiarity with individuals with brain injury influenced their attributions to either brain injury or adolescence for the undesirable behaviour of an adolescent with brain injury. It was predicted that in both scar conditions, participants who were more familiar with individuals with brain injury would attribute the undesirable behaviours more to the brain injury than participants with less familiarity, and that participants less familiar would attribute the behaviours more to adolescence than participants with more familiarity. This pattern occurred in the scar condition, but in the no scar condition, participants in both groups attributed the behaviours equally to the brain injury and adolescence. These results suggest that visible markers of injury prompt people with high familiarity to attribute the undesirable behaviours more to the brain injury. However, people with low familiarity show the opposite effect, the scar apparently prompting them to attribute the behaviours more to adolescence, suggesting that they discount the brain injury as a cause for the adolescent's undesirable behaviour when there are visible markers of injury.

The results from the high familiarity group relate to Rohmer and Louvet's (2009) finding that visible disabilities are more salient than gender or ethnicity as they suggest that visible markers of brain injury are more salient than adolescence when a person has high familiarity with individuals with brain injury, but not when they have low familiarity. To summarise, familiarity with individuals with brain injury has no effect on attributions when there are no visible markers of injury. In contrast, when there are visible markers of injury, people with high familiarity take 
more account of the brain injury (higher attributions to brain injury), relative to people with low familiarity (higher attributions to adolescence) when attributing causes for an adolescent's undesirable behaviour.

\section{Effects of Visibility and Brain Injury}

Experiment 1 supports previous research by McClure et al. (2006; 2008), who found that visible markers of injury prompt people to attribute the brain injured adolescent's undesirable behaviour equally to adolescence and brain injury, whereas when there are no visible markers of injury people attribute the behaviours more to adolescence than the brain injury. This suggests that the presence of a scar activates information about brain injuries (availability heuristic) and in the absence of a visible marker of injury, stereotypes about adolescent norms are activated more than information about brain injuries. This attribution pattern occurred even though the participants were advised that the adolescent had suffered a brain injury. These findings relate to Rohmer and Louvet's (2009) research; they found that visible markers of disability prompt people to view the disability as more salient than gender or ethnicity. The no scar condition findings also illustrate a common misconception regarding brain injuries, specifically the belief that once physical injuries are healed then the individuals' brain injury has also recovered and any behavioural problems resulting from the injury have disappeared (Swift \& Wilson, 2001).

One exception to the attribution pattern found was the behaviour 'lacks motivation', which was attributed more to adolescence than brain injury in both scar conditions in the current research and McClure et al.'s $(2006 ; 2008)$ research. This suggests that 'lacks motivation' may be more representative of adolescent behaviour than brain injuries. One discrepancy in the current research is the 
apparent conflicting results between Experiment 1 and 2. Experiment 1 showed that when the cause of the brain injury was not identified, people attributed the behaviours more to adolescence than brain injury in the no scar condition and equally to adolescence and brain injury in the scar condition. However, under the same conditions in Experiment 2, the behaviours were attributed equally to adolescence and brain injury in both scar conditions. A possible reason for this effect is age; the participants in Experiment 1 had a median age in the 20-29 age bracket, whereas participants in Experiment 2 had a median age of 30-39, suggesting that when there are no visible markers of injury, younger people discount the injury as a cause of the undesirable behaviour more than older people.

The findings of Experiment 1 and McClure et al.'s (2006; 2008) research show that having no visible markers of brain injury is problematic and can result in a failure to allow for the brain injury as a cause of undesirable behaviour. This lack of allowance for the subsequent effects of the brain injury may result in insufficient care and treatment. These studies show that there is a cost to having non-visible brain injuries (less allowance for the brain injury as a cause of the undesirable behaviour) and a benefit to having visible markers of injury (more allowance for the brain injury as a cause of the undesirable behaviour) (McClure, 2009). Therefore, some negative consequences of non-visible brain injuries may be similar to that experienced by individuals with visible disabilities (Matthews \& Harrington, 2000; McClure, 2009). Stigma research shows that people with visible disabilities often experience a cost (prejudice and discrimination) associated with having their disability visible (Latner et al., 2005; Matthews \& Harrington).

To summarise, Experiment 1 showed that when no information was given about the brain injury (which often occurs in everyday situations), the visibility of 
the injury had no impact on attributions for an adolescent's undesirable behaviour, but when participants were informed about the injury, visible markers of injury do impact on attributions. Experiment 2 showed that whether a brain injury was visible or not, had no effect when the described cause of the injury was external (brain tumour) and when the cause of the injury was not identified, but the visibility of the injury did affect attributions for undesirable behaviour when the described cause was internal (abusing illegal drugs). Visible markers of injury did impact on participants' attributions when they were more familiar with individuals with brain injury and when they were less familiar, although in opposing ways. When there were visible markers of injury, participants with more familiarity attributed the behaviours more to brain injury than participants with less familiarity. In contrast, participants with less familiarity attributed the behaviours more to adolescence than participants with more familiarity.

\section{Stereotyping, Prejudice, Discrimination and Stigma}

The finding that participants attribute undesirable behaviours more to adolescence than brain injury when they were informed about the brain injury and no visible markers of injury are present may imply that the participants engaged in stereotyping, particularly as past research found that these behaviours were equally likely following a brain injury and during adolescence (McClure et al., 2006). Furthermore, when no information about the brain injury is given, participants attribute the behaviours more to adolescence regardless of the visibility of the brain injury, which supports the idea that being given information about an adolescent's brain injury could reduce stereotyping and the resulting discrimination, at least when visible markers of injury are present. A possible interpretation is that visible markers of injury and being given information about an 
adolescent's brain injury are moderators in the relationship between responsibility and attributions to adolescence or brain injury.

Stereotypes are collectively agreed upon ideas or notions about particular groups that can be quickly accessed (Hamilton \& Sherman, 1994). Arguably, the undesirable behaviours described (sleeps a lot, lacks motivation, angers quickly and lacks self-confidence) are highly typical adolescent behaviours and the participants explicitly and implicitly linked them to adolescence (stereotyping), which influenced subsequent attributions. A recent study by Gross and Hardin (2007) confirms that people (psychology students) explicitly and implicitly associate common adolescent behaviours with adolescents. However, in some instances adolescent stereotyping can be overruled by the visibility of the disability, as shown in the current research. It is possible this occurred as visible disabilities are superordinate social categories. Rohmer and Louvet (2009) found that visible disabilities were a superordinate social category when people describe a person in a wheelchair. That is, the disability was more salient than gender or ethnicity. Rohmer and Louvet's findings potentially explain why the scar prompted participants to attribute the behaviours equally to adolescence and the brain injury, the scar made the disability more salient.

When the described cause was internal (abusing illegal drugs), participants attributed the behaviours more to brain injury than adolescence in the scar condition, with the reverse found in the no scar condition. In this scenario, it is possible that the scar, along with the description 'abusing illegal drugs' (eliciting thoughts of young people "spaced" out on drugs) resulted in the disability being highly salient and overruled stereotypical beliefs about adolescent behaviours. 


\section{Responsibility and Weiner's Attribution Theory}

The results lend partial support for Weiner's attribution theory. Participants assigned more responsibility to the adolescent for his undesirable behaviour in the abusing illegal drugs condition (internal cause), than the tumour condition (external cause) and when the cause of the brain injury was not identified. Furthermore, when there were no visible markers of injury and the cause was internal, participants attributed the undesirable behaviours more to adolescence than brain injury. However, when there were visible markers of injury, participants attributed the behaviours more to the brain injury than adolescence. Therefore in this study, visible markers of injury influenced people's attributions for an adolescent's undesirable behaviour when the cause was internal, but not when the cause was external and the cause was not identified. However, visible markers of injury do not influence the assigning of responsibility in each causal condition, suggesting that visible markers of injury moderate the relationship between controllability and behavioural responses (along with responsibility) in Weiner's (1995; 2006) attribution theory.

\section{Implications for Rehabilitation}

Visible markers of brain injury have been shown to influence people's attributions for an adolescent's undesirable behaviour in a number of studies (McClure et al., 2006; 2008). The implications of this pattern are significant. When an adolescent has no visible markers of injury, the public, family, friends and caregivers may attribute behaviours resulting from the brain injury to other causes, potentially resulting in less willingness to provide assistance and appropriate care and treatment. This is particularly relevant when the adolescent is perceived as responsible for their brain injury and visible markers of injury are absent. 
When the cause of the injury was abusing illegal drugs and there was no scar participants made higher attributions to adolescence than brain injury. This finding is noteworthy as it suggests that survivors of brain injury would be well advised to show discretion in telling others about the cause of their injury when it is internal and no visible signs of injury are present. This discretion may be warranted as it may result in less allowance being given to the brain injury as a cause of undesirable behaviours. This is speculative and can be explored in future research.

The findings in this research can be used when developing campaigns aimed at increasing the public's awareness of the implications of brain injuries. Campaigns could highlight typical behaviours resulting from brain injuries and inform the public about the effects of visible and non-visible brain injuries. Specifically, once visible markers of brain injury have healed, this does not mean that the subsequent problems or behaviours resulting from the brain injury have recovered or disappeared. Although past research has shown that the effects of education are small (Stuber, Meyer \& Link, 2008), it is still worthwhile. Other avenues include informing brain injury professionals who can then advise their patients and immediate family and caregivers about the effects of having visible and non-visible brain injuries and the possible consequences of disclosing or not disclosing a disability.

\section{Limitations}

The familiarity results should be viewed with caution as items 3 to 8 (high familiarity condition) on the familiarity scale described the brain injury as 'severe', which caused confusion for some participants as they were unsure about how to grade the brain injury. This wording followed that used by Corrigan et al. (2005), but it may have caused some participants to select items describing scenarios that 
included items 1 and 2 (low familiarity condition), which did not have the words 'severe' in them. Future research could remove 'severe' to avoid this issue occurring again. Furthermore, due to the low number of participants who were familiar with individuals with brain injury the familiarity scale was organised into a two category measure.

Asking adults to make judgements about adolescents' behaviour may have caused some confusion for the adults with children or adolescents, due to their role as protectors and carers of children (Martin et al., 2007). Confusion may arise because parents may view the adolescents as children and believe the responsibility for their behaviour still resides partially with them. Therefore asking participants about whether they are parents or not is recommended to compare groups with and without children. This study described an adolescent male with brain injury; the findings may differ if the protagonist was a female or an adult. A further limitation of this study is not explicitly assigning blame or no blame for the abusing illegal drugs and brain tumour conditions. Previous research found that explicitly assigning blame or not assigning blame was related to prejudice and discriminatory practices (Linden et al., 2007). For instance, participants could have assumed that the adolescent was not to blame for his brain tumour (received infected blood transfusion) or they could have assumed he was (as a result of taking drugs). Similarly they could have assumed he was not to blame for abusing illegal drugs (his best friend was killed and he started self medicating) or they could have assumed he was (partying with friends and knowingly taking drugs).

\section{Future Research}

Possible future extensions to the current research include: asking participants if they have children, or care for children and compare this group with 
a group who have no children, to establish whether having or caring for children influences attributions. As previously mentioned, the familiarity descriptions could remove the word 'severe' before brain injury, and have the same description of brain injury for all levels of injury. Prior to further research on attributions, a manipulation check could be performed to examine the general public's beliefs regarding typical adolescent behaviours and behaviours resulting from a brain injuury, as these may differ from students' beliefs. Also, research could explicitly assign blame for external and internal causes of brain injury. Extending the current research by changing the protagonist to a teenage girl and older people would enable evaluation of gender and age effects.

Examining carers' and health professionals' attitudes towards survivors of brain injury is desirable, especially when the survivors of brain injury have external causes of injury and there are no visible markers of injury. This would provide information about the impact that perceived responsibility for an injury and visible markers of injury have on care provided.

This research and McClure et al.'s $(2006 ; 2008)$ research provides valuable information about the factors that influence attributions for the undesirable behaviour resulting from an adolescents' brain injury. Results from these studies suggest that visible markers of injury, causes of injury and familiarity with individuals with brain injury may moderate the relationship from responsibility to attributions for an adolescent's undesirable behaviour. Weiner et al.'s (1988) attribution research shows that emotions are mediators in the relationship between responsibility and helping behaviours. Future research could combine aspects of this research and Weiner et al.'s research to clarify under what conditions perceived responsibility influences participants' attributions to brain injury or 
adolescence, and under what conditions perceived responsibility leads to stigma and discrimination aimed at adolescents with brain injury. Testing this model would involve two distinct goals. The first would examine the relationship between responsibility and attributions of undesirable behaviour, with emotions mediating this relationship and familiarity, causes of injury and visibility of injury moderating the relationship. The second goal would be to examine the relationship between responsibility and discriminatory and helping behaviour using the same mediators and moderators as above.

\section{Conclusion}

The findings from this research show that visible markers of brain injury, the aetiology of an injury and familiarity with individuals with brain injury influence people's attributions for brain injured adolescents' undesirable behaviour. Specifically, a lack of visible markers of injury influences attributions when an adolescent is perceived as responsible for causing their injury, but not when the adolescent is not responsible or the cause of the injury is not identified. Visible markers of brain injury influence people with high familiarity to take more account of the brain injury as the cause of the adolescent's undesirable behaviour, but people with low familiarity show the opposite effect. Notwithstanding the limitations discussed, this research provides useful information which can be used by professionals and caregivers to inform survivors about these effects and used in campaigns to educate the public. 


\section{References}

Abelson-Mitchell, N. (2008). Epidemiology and prevention of head injuries: Literature review. Journal of Clinical Nursing, 17, 46-57.

ACC (2006). Traumatic brain injury: Diagnosis, acute management and $\begin{array}{lll}\text { rehabilitation. } & \text { Retrieved } & \text { from }\end{array}$ http://www.nzgg.org.nz/guidelines/0129/ACC14261.pdf 4th November, 2009.

Allport, G.W. (1958). The Nature of Prejudice. (abridged). Garden City, New York: Doubleday (original work published in 1954).

Brain Injury Association of America (2009). Retrieved from http://www.biausa.org/aboutbi.htm on the 10th November 2009.

Brain Injury New Zealand (2009). Retrieved from http://www.braininjury.org.nz/braininjury gettinghelp.html on the 4th November 2009.

Chamberlain, D.J. (2006). The experience of surviving traumatic brain injury. Journal of Advanced Nursing, 54, 407-417.

Cline, R.J.W. \& McKenzie, N.J. (2000). Dilemmas of disclosure in the age of HIV/AIDS. In: Braithwaite D.O., \& Thompson, T.L., editors. Handbook of communication and people with disabilities: Research and application. Mahwah, N.J.: Lawrence Erlbaum: p 468.

Corrigan, P.W., Edwards, A.B., Green, A., Diwan, S.L., \& Penn, D.L. (2001). Prejudice, social distance, and familiarity with mental illness. Schizophrenia Bulletin, 27, 219-225.

Corrigan, P.W., Green, A., Lundin, R., Kubiak, M.A., \& Penn, D.L. (2001). Familiarity with and social distance from people who have serious mental illness. Psychiatric Services, 52, 953-958. 
Corrigan, P.W., Lurie, B.D., Goldman, H.H., Slopen, A.M., Medasani, K., \& Phelan, S. (2005). How adolescents perceive the stigma of mental illness and alcohol abuse. Psychiatric Services, 56, 544-55.

Corrigan, P., Markowitz, F.E., Watson, A., Rowan, D., \& Kubiak, M.A. (2003). An attribution model of public discrimination towards persons with mental illness. Journal of Health and Social Behaviour, 44, 162-179.

Corrigan, P.W., \& Wassel, A. (2008). Understanding and influencing the stigma of mental illness. Journal of Psychosocial Nursing, 46, 42-48.

Dawson, D.R., \& Chipman, M. (1995). The disablement experienced by traumatically brain-injured adults living in the community. Brain Injury, 9, 339-353.

Draper, K., \& Ponsford, J. (2008). Cognitive functioning ten years following traumatic brain injury and rehabilitation. Neuropsychology, 22, 618-625.

Fiske, S.T., Kenny, D.A., \& Taylor, S.E. (1982). Structural models for the mediation of salience effects on attribution. Journal of Experimental Psychology, 18, 105-127.

Gouvier, W.D., Prestholdt, P.H., \& Warner, M.S. (1988). A survey of common misconceptions about head injury and recovery. Archives of Clinical Neuropsychology, 3, 331-343.

Goffman, E. (1963). Stigma: notes on the management of spoiled identity. New York: Simon and Schuster.

Gross, E.F., \& Hardin, C.D. (2007). Implicit and explicit stereotyping of adolescents. Social Justice Research, 20, 140-160. 
Guilmette, T.J., \& Paglia, M.F. (2004). The public's misconceptions about traumatic brain injury: A follow up survey. Archives of Clinical Neuropsychology, 19, 183-189.

Hamilton, D.L., \& Sherman, J.W. (1994). Stereotypes. In: Wyer, R.S., \& Drull, T.K. (Eds), Handbook of social cognition, Vol. 1: Basic processes $\left(2^{\text {nd }} \mathrm{ed}.\right)$ : Hillsdale, NJ: Erlbaum: pp 1-68.

Holmes, P.E., Corrigan, P.W., Williams, P., Canar, J., \& Kubiak, M.A. (1999). “Changing attitudes about schizophrenia". Schizophrenia Bulletin, 25, 447456.

Kim, E., Lauterbach, E.C., Reeve, A., Arciniegas, D.B., Coburn, D.B., Mendex, M.F., ....... Coffey, E.C. (2007). Neuropsychiatric complications of traumatic brain injury: A critical review of the literature (A report by the ANJPA committee on Research). The Journal of Neuropsychiatry and Clinical Neurosciences, 19, 106-128.

Latner, J.D., Stundard, A.J., \& Wilson, G.T. (2005). Stigmatized students: Age, sex and ethnicity effects in the stigmatization of obesity. Obesity Research, 13, $1226-1231$.

Linden, M.A., Hanna, D., \& Redpath, S.J. (2007). The influence of aetiology and blame on prejudice towards survivors of brain injury. Archives of Clinical Neuropsychology, 22, 665-673.

Link, B.G., \& Phelan, J.C. (2001). Conceptualizing stigma. Annual Review of Sociology, 27, 363-385.

Link, B.G., Struening, E.L., Neese-Todd, S., Asmussen, S., \& Phelan, J.C. (2001). The consequences of stigma for the self-esteem of people with mental illnesses. Psychiatric Services, 52, 1621-1628. 
Lucas, J.A., \& Addeo, R. (2006). Clinical Neuropsychology - Traumatic Brain Injury and Postconcussion Syndrome. Washington: American Psychological Association. Snyder, P.J., Nussbaum, P.D., \& Robins, D.L.: pp 351-380.

Martin, J.K., Pescosolido, B.A., Olafsdottir, S., \& McLeod, J.D. (2007). The construction of fear: Americans' preferences for social distance from children and adolescents with mental health problems. Journal of Health and Social Behavior, 48, 50-67.

Martin, J.K., Pescosolido, B.A., \& Tuch, S.A. (2000). Of fear and loathing: The role of 'disturbing behaviour', labels, and causal attributions in shaping public attitudes toward people with mental illness. Journal of Health and Social Behaviour, 41, 208-223.

Matthews, C.K., \& Harrington, N.G. (2000). Invisible disability. In: Braithwaite D.O., \& Thompson, T.L., editors. Handbook of Communication and People with Disabilities: Research and Application. Mahwah, N.J.: Lawrence Erlbaum: pp 405-421.

McClure, J. (2009). Social psychological factors affecting brain injury rehabilitation: Attributions and related processes. Victoria: University of Wellington.

McClure, J., Buchanan, S., McDowall, J., \& Wade, K. (2008). Attributions for behaviours of persons with brain injury: The role of perceived severity and time since injury. Brain Injury, 22, 639-648.

McClure, J., Devlin, M.E., McDowall, J., \& Wade, K. (2006). Visible markers of brain injury influence attributions for adolescents' behaviour. Brain Injury, 20, 1029-1035. 
Miller, N.B., \& Sammons, C.C. (1999). Everybody's Different: Understanding and Changing Our Reactions to Disabilities. Baltimore: Paul H. Brookes: pp 239-264.

Phelan, J., Link, B.G., \& Dovidio, J.F. (2008). Stigma and prejudice: One animal or two? Social Science and Medicine, 67, 358-367.

Redpath, S.J., \& Linden, M.A. (2004). Attitudes towards behavioural versus organic acquisition of brain injury. Brain Injury, 18, 861-869.

Rohmer, O., \& Louvet, E. (2009). Describing persons with disability: Salience of disability, gender, and ethnicity. Rehabilitation Psychology, 54, 76-82.

Snyder, P.J., Nussbaum, P.D., \& Robins, D.L. (2006). Clinical Neuropsychology: A Pocket Handbook for Assessment, $2^{\text {nd }}$ ed. Washington, DC, US: American Psychological Association.

Stuber, J., Meyer, I., \& Link, B. (2008). Stigma, prejudice, discrimination and health. Social Science and Medicine, 67, 351-357.

Swift, T.L., \& Wilson, S.L. (2001). Misconceptions about brain injury among the general public and non-expert health professionals: An exploratory study. Brain Injury, 15, 149-165.

Tsaousides, T., Ashman, T., Seter, Col. (2008). The psychological effects of employment after traumatic brain injury: Objective and subjective indicators. Rehabilitation Psychology, 53, 456-463.

Tuch, S.A., \& Hughes, M. (1996). "Whites's racial policy attitudes." Social Science Quarterly, 77, 723-745.

Tversky, A., \& Kahneman, D. (1974). Judgement under uncertainty: Heuristics and bias. Science, 185, 1124-1131. 
Weiner, B. (1995). Judgments of Responsibility: A Foundation for a Theory of Social Conduct. New York: Guilford Press.

Weiner, B. (2006). Social Motivation, Justice, and the Moral Emotions: An Attributional Approach. New Jersey: Lawrence Erlbaum Associates.

Weiner, B., Perry, R.P., \& Magnusson, J. (1988). An attributional analysis of reactions to stigmas. Journal of Personality and Social Psychology, 55, 738-748.

Willer, B., Johnson, W.E., Rempel, R.G., \& Linn, R. (1993). A note concerning misconceptions of the general public about brain injury. Archives of Clinical Neuropsychology, 8, 461-465.

Zahn, M.A. (1973). Incapacity, impotence and invisible impairment: Their effects upon interpersonal relations. Journal of Health and social Behavior, 14, 115-123. 
Appendix A

Photos: The following photos were used for both Experiments.

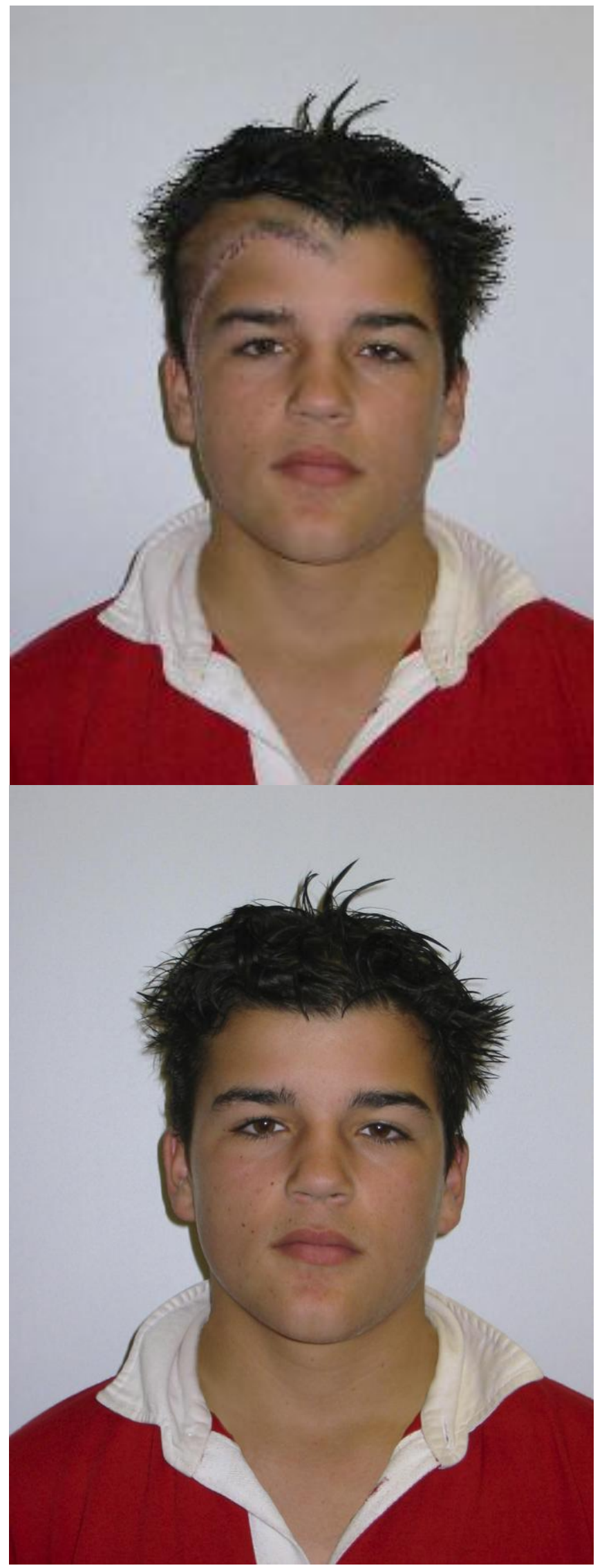




\section{Appendix B}

\section{Experiment 1 Materials}

\section{Information Sheet}

My name is Lyn Foster and I am a Masters Psychology student at Victoria University being supervised by Professor John McClure and Associate Professor John McDowall. I am currently researching people's opinions regarding behaviours of adolescents. This research has been approved by the University ethics committee.

If you agree to participate in our research we require you to view a photo of an adolescent and read a small caption about the individual and then complete a short survey questionnaire. The questionnaire includes questions like, "please rate both of the following explanations for Chris's lack of self-confidence". This should take no longer than five minutes to complete. While completing the survey you are free to withdraw at any point prior to the survey being completed and handed in.

Completion of the questionnaire indicates your consent to take part in this research.

In order to protect your privacy the survey is completely anonymous, so please do not put your name anywhere on the survey form. The information provided is coded by number and you will never be identified in the research or any presentation or publication. The survey data will be kept for a minimum of five years after publication. Your coded survey may be passed on to other competent researchers as required by some scientific journals and organisations and your survey may be used in other related research. A copy of your survey will be kept by Professor John McClure.

The information you provide may be used in my Masters thesis and submitted for assessment and the findings may be published in scientific journals or presented at scientific conferences.

If you would like to receive information regarding the findings of this research please put your contact details on the separate sheet provided for this. The findings will be available by March 2010 and will be emailed to you by either myself or John McClure. This form will not be kept with the completed survey questionnaires, it will be stored separately. Thank you for considering participating in this research.

If, at a later time you have any questions about this survey or would like further information feel free to contact either John McClure or myself using the following emails:

lynette.foster@vuw.ac.nz john.mcclure@vuw.ac.nz 


\section{Vignette}

The italicised words in the vignette were taken out for the "no information

about the head injury' condition.

"Above is a photo of Chris. Chris lives in Wellington and has been going to school, where his favourite class is social studies as he enjoys learning about other cultures as well as New Zealand's culture and bits about history. He would like to become a historian when he gets older, as they get to travel around to different countries and find out about their histories. Chris has suffered from a head injury, which has injured his brain at the time of becoming an adolescent. Since the injury, Chris' parents have noticed some changes in his behaviour that they are a little concerned about. He lacks self-confidence, whereas previously he was more sure of himself. They've also noticed that where Chris used to be quite a calm person, he now appears to anger quickly. Chris appears to be lacking motivation for things he always wanted to do. Chris' parents have also noticed that he now sleeps a lot, often sleeping in and then nodding off again in the afternoon. " 


\section{Questionnaire}

This questionnaire asks about your opinions; there are no right or wrong answers.

1. Please rate both of the following explanations for Chris's lack of selfconfidence. (Circle a number for each explanation)

(a) It is likely to be due to head injury or some other medical condition

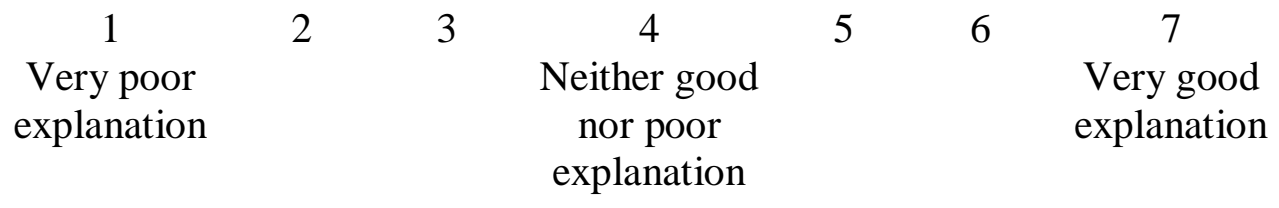

(b) It is likely to be due to normal adolescence

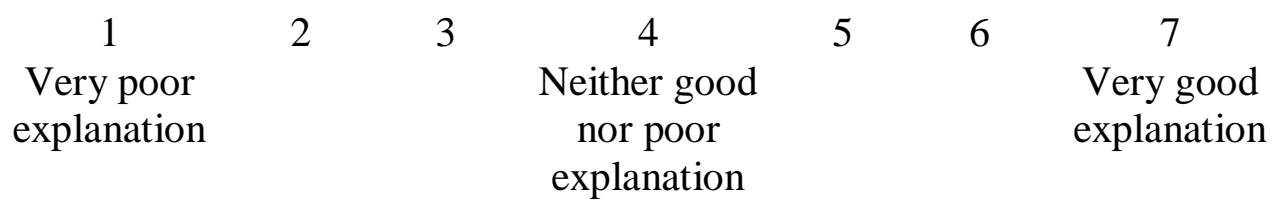

2. Please rate both of the following explanations for Chris's tendency to anger quickly. (Circle a number for each explanation)

(a) It is likely to be due to head injury or some other medical condition

$\begin{array}{ccccccc}1 & 2 & 3 & \begin{array}{c}4 \\ \text { Neither good } \\ \text { nor poor } \\ \text { explanation }\end{array} & 5 & 6 & \begin{array}{c}7 \\ \text { Very good } \\ \text { explanation }\end{array}\end{array}$

(b) It is likely to be due to normal adolescence

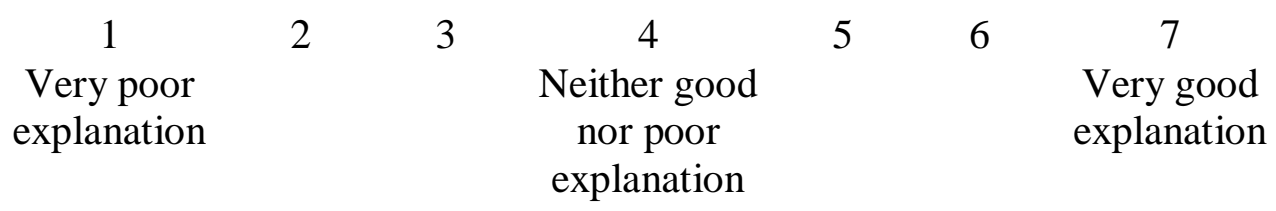

3. Please rate both of the following explanations for Chris's lack of motivation. (Circle a number for each explanation)

(a) It is likely to be due to head injury or some other medical condition

$\begin{array}{ccccccc}1 & 2 & 3 & \begin{array}{c}4 \\ \text { Neither good } \\ \text { nor poor } \\ \text { Very poor } \\ \text { explanation }\end{array} & 5 & 6 & \begin{array}{c}7 \\ \text { Very good } \\ \text { explanation }\end{array}\end{array}$


(b) It is likely to be due to normal adolescence

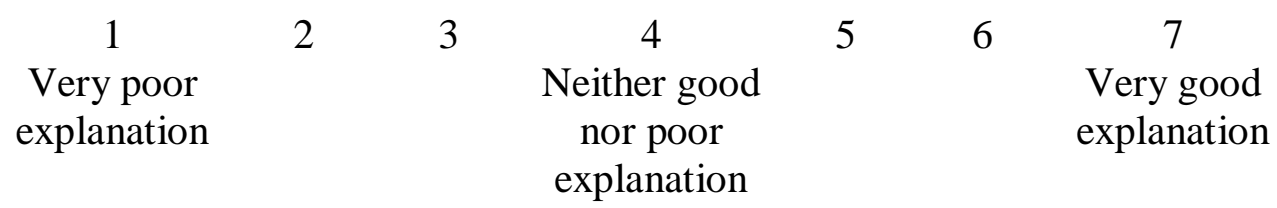

4. Please rate both of the following explanations for Chris sleeping alot. (Circle a number for each explanation)

(a) It is likely to be due to head injury or some other medical condition

$\begin{array}{ccccccc}1 & 2 & 3 & 4 & 5 & 6 & \begin{array}{c}7 \\ \text { Nery poor } \\ \text { explanation }\end{array} \\ \begin{array}{c}\text { Ner goor } \\ \text { explanation }\end{array} & & & \begin{array}{c}\text { Very good } \\ \text { explanation }\end{array}\end{array}$

(b) It is likely to be due to normal adolescence

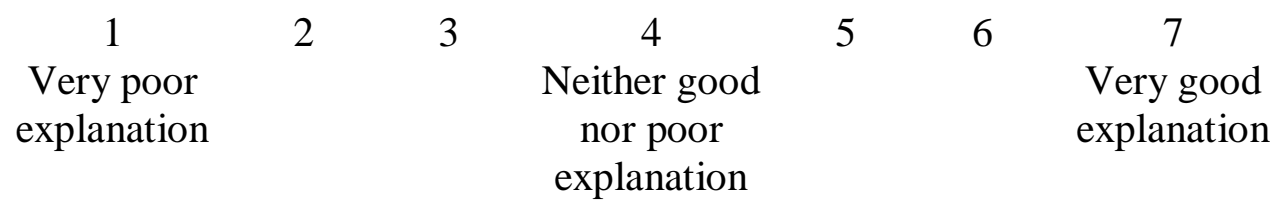

5. If you don't mind could you please indicate your age by circling the number next to the appropriate age group?

$\begin{array}{cccccc}1 & 2 & 3 & 4 & 5 & 6 \\ \text { Under } 20 & 20-29 & 30-39 & 40-49 & 50-59 & \text { Over } 60\end{array}$

6. Again if you don't mind giving this information could you please indicate your gender by circling the appropriate option?

Male Female 


\section{Debriefing Sheet}

Thank you for taking the time to participate in this research.

Previous research found that individuals attribute adolescents' inappropriate behaviour more to "being an adolescent" than the brain injury suffered when shown a picture of an adolescent with no signs of injury. However, when they are shown a picture of an adolescent with a scar on their head they attribute inappropriate behaviour equally to "being an adolescent" and the brain injury they suffered.

To further understand how people form these attributions this research examined whether information given about brain injury, responsibility and familiarity influenced individuals attributions to either brain injury or adolescence. That is, whether individuals attribute inappropriate behaviour differently when they are told an adolescent has suffered a brain injury as opposed to not being told about the brain injury. Also do attributions differ when people are aware that the adolescent was responsible or not for their injury and do individuals attribute inappropriate behaviour differently when they themselves are familiar with individuals with brain injury?

This type of research is important as some individuals with brain injuries are discriminated against. It is especially important with adolescent populations as it shows that behaviours which could be associated with their brain injury are being attributed to their stage of life (adolescence) which could result in less help and assistance from families and carers. The findings here can be used by government and agencies to inform and educate the public about how individuals attribute the behaviours of people with brain injury. Like the current mental health advertisements on television which are used to inform public about the discrimination that occurs for mentally ill people.

The photograph used in this study showing an adolescent male with a head injury was fictional as well as the information you read about the adolescent and how his injury occurred.

Once again thank you for taking the time to complete this survey. If you have questions or would like to discuss this research in more detail at a later time please contact me, lynette.foster@vuw.ac.nz or my supervisor John McClure, john.mcclure@vuw.ac.nz. 


\section{Appendix C}

\section{Experiment 2 Materials}

The information and debriefing sheets used for Experiment 2 were identical to those used in Experiment 1.

\section{Vignette}

The italicised words in the vignette were added for the 'brain tumour' condition and the bold words were added for the 'abusing illegal drugs' condition.

\footnotetext{
"Above is a photo of Chris. Chris lives in Wellington and has been going to school, where his favourite class is social studies as he enjoys learning about other cultures as well as New Zealand's culture and bits about history. He would like to become a historian when he gets older, as they get to travel around to different countries and find out about their histories. Chris has suffered from a head injury "as the result of a brain tumour", "as a result of abusing illegal drugs" which has injured his brain at the time of becoming an adolescent. Since the injury, Chris' parents have noticed some changes in his behaviour that they are a little concerned about. He lacks selfconfidence, whereas previously he was more sure of himself. They've also noticed that where Chris used to be quite a calm person, he now appears to anger quickly. Chris appears to be lacking motivation for things he always wanted to do. Chris' parents have also noticed that he now sleeps a lot, often sleeping in and then nodding off again in the afternoon. "
} 


\section{Questionnaire}

This questionnaire asks about your opinions; there are no right or wrong answers.

1. Please rate both of the following explanations for Chris's lack of selfconfidence. (Circle a number for each explanation)

(c) It is likely to be due to Chris's head injury

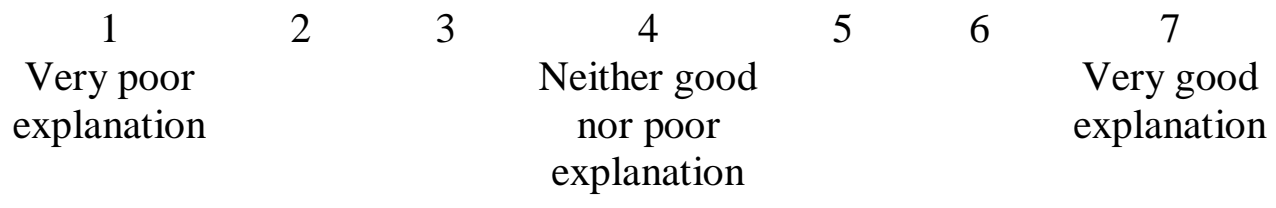

(d) It is likely to be due to normal adolescence

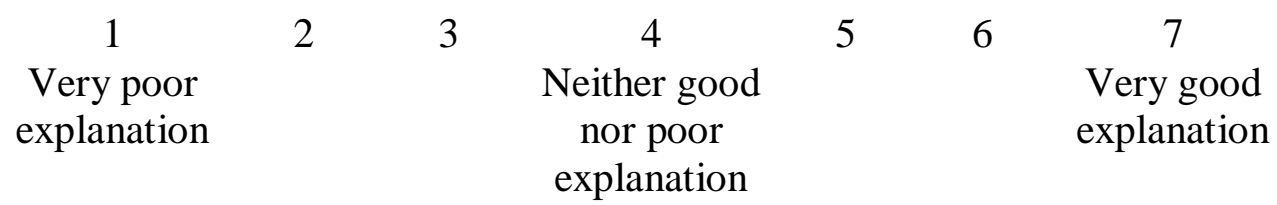

2. Please rate both of the following explanations for Chris's tendency to anger quickly. (Circle a number for each explanation)

(c) It is likely to be due to Chris's head injury

$\begin{array}{ccccccc}1 & 2 & 3 & \begin{array}{c}4 \\ \text { Neither good } \\ \text { ner poor } \\ \text { explanation }\end{array} & 5 & 6 & \begin{array}{c}7 \\ \text { Very good } \\ \text { explanation }\end{array}\end{array}$

(d) It is likely to be due to normal adolescence

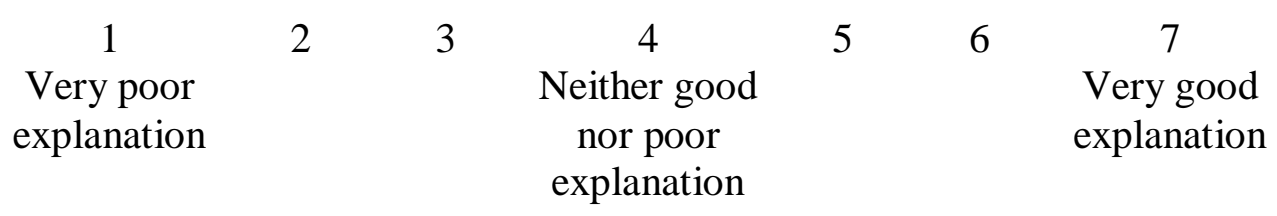

3. Please rate both of the following explanations for Chris's lack of motivation. (Circle a number for each explanation)

(c) It is likely to be due to Chris's head injury

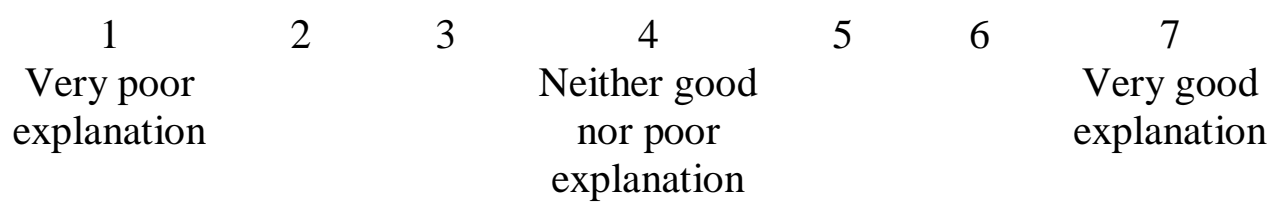


(d) It is likely to be due to normal adolescence

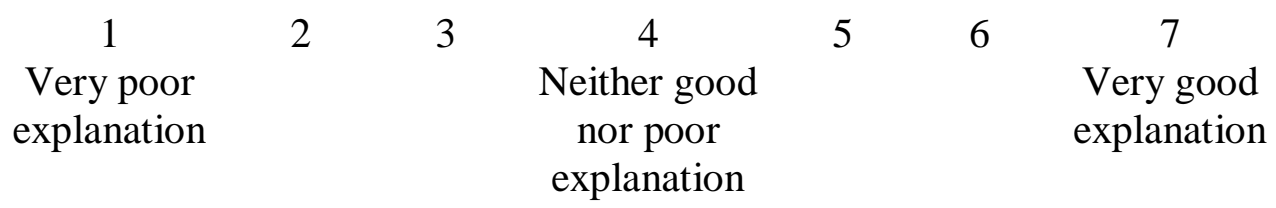

4. Please rate both of the following explanations for Chris sleeping alot. (Circle a number for each explanation)

(c) It is likely to be due to Chris's head injury

$\begin{array}{ccccccc}1 & 2 & 3 & \begin{array}{c}4 \\ \text { Neither good } \\ \text { nery poor } \\ \text { explanation }\end{array} & 5 & 6 & \begin{array}{c}7 \\ \text { explanation }\end{array} \\ \text { explanation }\end{array}$

(d) It is likely to be due to normal adolescence

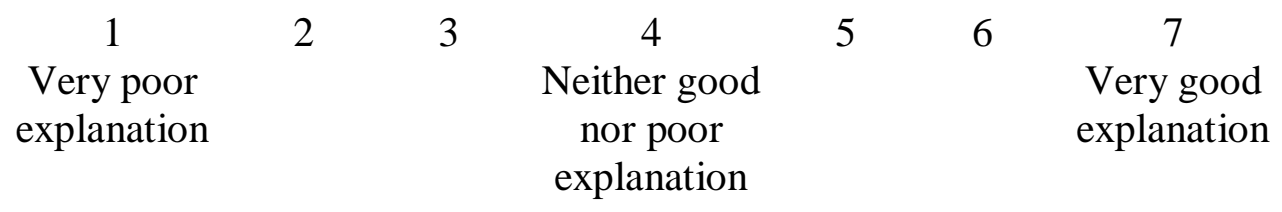

5. From the information you have about Chris, how severe do you think Chris's head injury probably was?

$\begin{array}{ccccccc}1 & 2 & 3 & 4 & 5 & 6 & 7 \\ \begin{array}{l}\text { Very } \\ \text { mild }\end{array} & & & \text { moderate } & & & \begin{array}{c}\text { Very } \\ \text { severe }\end{array}\end{array}$

6. From the information you have about Chris, how responsible, do you think, is Chris for his present condition?

$\begin{array}{ccccccc}1 & 2 & 3 & 4 & 5 & 6 & 7 \\ \begin{array}{c}\text { Not at all } \\ \text { responsible }\end{array} & & & \begin{array}{l}\text { Moderately } \\ \text { responsible }\end{array} & & & \begin{array}{c}\text { Very } \\ \text { responsible }\end{array}\end{array}$

7. From the information you have about Chris, how controllable, do you think, is the cause of Chris' present condition?

$\begin{array}{ccccccc}1 & 2 & 3 & 4 & 5 & 6 & 7 \\ \begin{array}{c}\text { Not at all } \\ \text { controllable }\end{array} & & & \begin{array}{c}\text { Moderately } \\ \text { controllable }\end{array} & & & \\ \text { Very } \\ \text { controllable }\end{array}$


8. How familiar are you with people with brain injury? Choose the statement which is most accurate for you, and circle the number next to it.

1 I have never observed a person with brain injury

2 I have watched a television show that included a person with brain injury

3 I have observed a person with severe brain injury

$4 \quad$ I have been in a class with a person with severe brain injury

5 A friend of the family has a severe brain injury

6 I have a relative who has a severe brain injury

$7 \quad$ I live with a person with a severe brain injury

8 I have a severe brain injury

9. If you don't mind, could you please indicate your age by circling the number next to the appropriate age group?

$\begin{array}{cccccc}1 & 2 & 3 & 4 & 5 & 6 \\ \text { Under } 20 & 20-29 & 30-39 & 40-49 & 50-59 & \text { Over } 60\end{array}$

10. Also, could you please indicate your gender by circling the appropriate option?

Male Female 